\title{
Aluminum Removal and Sodium Hydroxide Regeneration from Hanford Tank Waste by Lithium Hydrotalcite Precipitation Summary of Prior Lab-scale Testing
}

\author{
Sebastien Guillot (AREVA Federal Services LLC) \\ Washington River Protection Solutions \\ Richland, WA 99352 \\ U.S. Department of Energy Contract DE-AC27-08RV14800

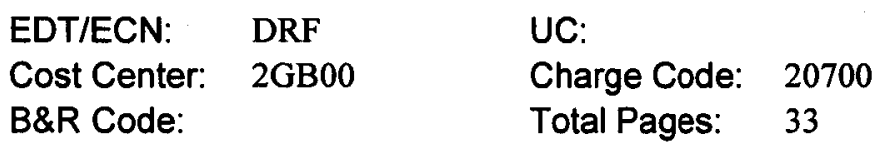

Key Words: Lithium Hydrotalcite (LiHT), Aluminum, Precipitation, Lithium Hydroxide, Double-Shell Tank Supernatant Simulant, Single-Shell Tank Supernatant Simulant, TRL3 Validation Tests, Georgia Tech, 222-S Laboratory.

Abstract: Scoping laboratory scale tests were performed at the Chemical Engineering Department of the Georgia Institute of Technology (Georgia Tech), and the Hanford 222-S Laboratory, involving double-shell tank (DST) and single-shell tank (SST) Hanford waste simulants. These tests established the viability of the Lithium Hydrotalcite precipitation process as a solution to remove aluminum and recycle sodium hydroxide from the Hanford tank waste, and set the basis of a validation test campaign to demonstrate a Technology Readiness Level of 3.

TRADEMARK DISCLAIMER. Reference herein to any specific commercial product, process, or service by trade name, trademark, manufacturer, or otherwise, does not necessarily constitute or imply its endorsement, recommendation, or favoring by the United States Government or any agency thereof or its contractors or subcontractors.

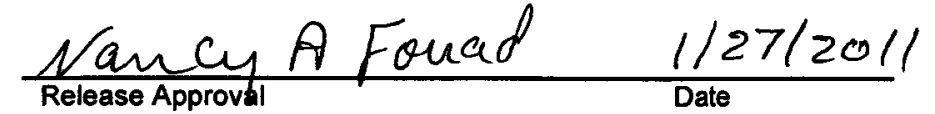

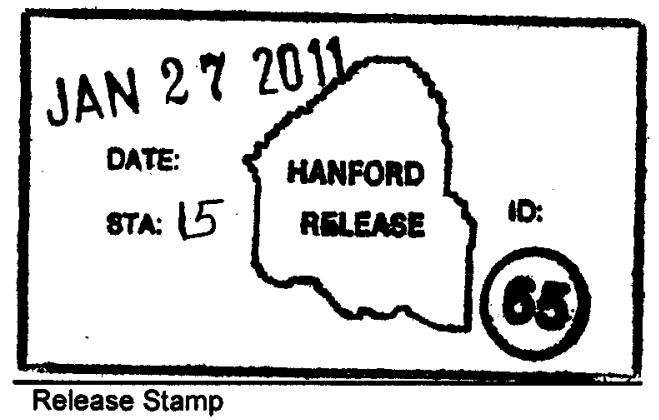

\section{Approved For Public Release}




\section{Aluminum Removal and Sodium Hydroxide Regeneration from Hanford Tank Waste by Lithium Hydrotalcite Precipitation}

\section{Summary of Prior Lab-scale Testing}

Sebastien Guillot

AREVA Federal Services LLC

Date Published

December 2010

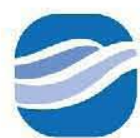

\section{washingtonriver}

protectionsolutions

P.O. Box 850

Richland, Washington 99352

Prepared for the U.S. Department of Energy

Assistant Secretary for Environmental Management

Contractor for the U.S. Department of Energy

Office of River Protection under Contract DE-AC27-08RV14800 
RPP-48376, Rev. 0

\begin{abstract}
Scoping laboratory scale tests were performed at the Chemical Engineering Department of the Georgia Institute of Technology (Georgia Tech), and the Hanford 222-S Laboratory, involving double-shell tank (DST) and single-shell tank (SST) Hanford waste simulants. These tests established the viability of the Lithium Hydrotalcite precipitation process as a solution to remove aluminum and recycle sodium hydroxide from the Hanford tank waste, and set the basis of a validation test campaign to demonstrate a Technology Readiness Level of 3.
\end{abstract}

\title{
KEY WORDS
}

Lithium Hydrotalcite (LiHT), Aluminum, Precipitation, Lithium Hydroxide, Double-Shell Tank Supernatant Simulant, Single-Shell Tank Supernatant Simulant, TRL3 Validation Tests, Georgia Tech, 222-S Laboratory. 
RPP-48376, Rev. 0

\section{EXECUTIVE SUMMARY}

The U.S. Department of Energy (DOE), Office of River Protection, is constructing a Waste Treatment and Immobilization Plant (WTP) for the treatment and vitrification of the underground tank wastes stored at the Hanford site. The WTP will pre-treat the waste to separate high-level (HLW) and low-activity waste (LAW) fractions. Aluminum containing sludges constitute a significant fraction of the Hanford waste and will be leached with sodium hydroxide in the pretreatment facility of the WTP. In order to facilitate the leaching, a large quantity of sodium hydroxide must be added to the waste. To minimize the large volume of sodium hydroxide required and ease processing of aluminum bearing sludges, AREVA has invented and patented the Lithium Hydrotalcite process ( $\mathrm{LiHT}$ ), for aluminum removal and sodium hydroxide regeneration from Hanford waste.

As a prime contractor to the U.S. DOE, Washington River Protection Solutions, LLC (WRPS) prepares long term strategic planning options/evaluations to accomplish the mission of the River Protection Plan (RPP), including evaluation and development of supplemental pretreatment options for Hanford tank waste. The LiHT process is one option to be evaluated. AREVA was contracted by WRPS under the "Lithium Hydrotalcite Technology Readiness Confirmation and Closure project", to assemble the documentation package for advancing the LiHT demonstration documentation and testing to the point where a Technology Readiness Assessment can be conducted. Scoping laboratory scale tests were performed at the Chemical Engineering Department of the Georgia Institute of Technology (Georgia Tech), and the Hanford 222-S Laboratory, involving double-shell tank (DST) and single-shell tank (SST) waste simulants.

In the case of the DST simulant (relatively low in phosphate), the product was the anticipated Li-hydrotalcite that rapidly precipitated in high yield. The Li-hydrotalcite formed from the DST supernate simulants were easily filterable solids, and were readily decontaminated. After four water washes the filter cake was a fluffy white material made of $<100 \mu \mathrm{m}$ agglomerates made of smaller crystallites. The crystallites are $\sim 5 \mu \mathrm{m}$ diameter platelets with $<1 \mu \mathrm{m}$ thickness. Chemical and mineralogical analyses of the filtrate, filter cake, and wash waters indicate a removal of $90+$ wt $\%$ of the dissolved Al for the DST simulant that generated the expected quantity of sodium hydroxide as a by-product of the reaction. The dried product may be suitable for Class C disposal or if this is not possible, used as a LAW glass former. The hydroxide enhanced filtrate may be recycled to leach additional aluminum from sludge or fed-forward to WTP for final treatment. In addition, test results indicate that phosphorus was removed with the hydrotalcite precipitate, which has the potential to mitigate line plugging and equipment fouling issues that have been associated with phosphate precipitates in the Tank Farm. For the SST simulant (relatively high in phosphate), the main competing reaction to the formation of lithium hydrotalcite appears to be the rapid formation of lithium phosphate. Adding excess Li to the solution to satisfy the phosphate demand did result in the formation of lithium hydrotalcite. Further parametric tests should be performed to characterize the two competing reactions, and determine the proper Lithium addition to ensure high reaction yield.

These preliminary tests set the basis for a validation testing campaign performed in 2010 to demonstrate a Technology Readiness Level of 3 , and prepare a development plan to further mature the process for integration into the overall WTP process. 


\section{TABLE OF CONTENTS}

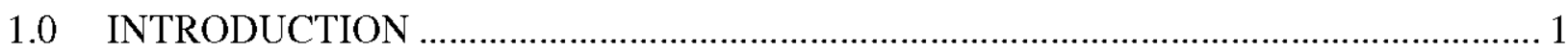

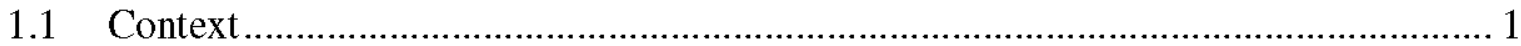

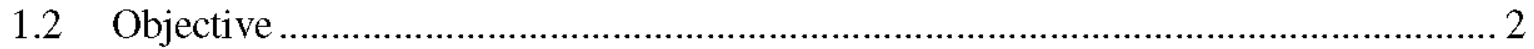

1.3 Technology Heritage .................................................................................... 3

2.0 SCOPING TESTS PERFORMED AT THE GEORGIA TECH LABORATORY ............... 4

2.1 Purpose

2.2 Test Configuration ..................................................................................... 4

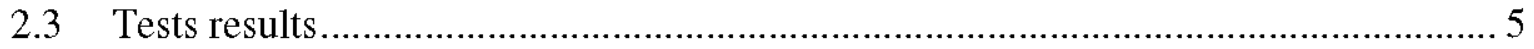

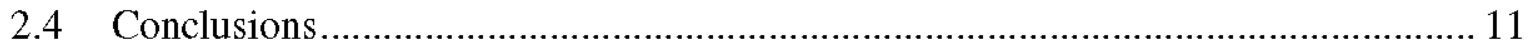

3.0 SCOPING TESTS PERFORMED AT THE 222-S LABORATORY ……....................... 11

3.1 Purpose

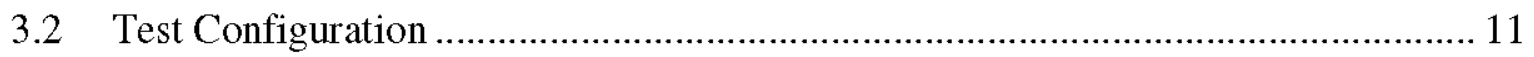

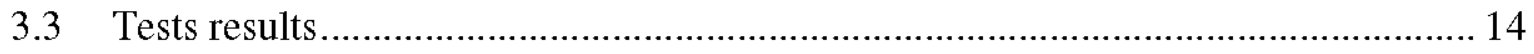

3.3.1 Double Shell Tank Simulant .................................................................. 14

3.3.2 Single Shell Tank Simulant …………………….................................. 17

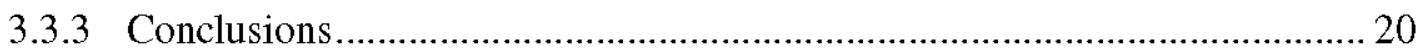

4.0 GENERAL CONCLUSIONS AND RECOMMENDATIONS FROM THE TWO

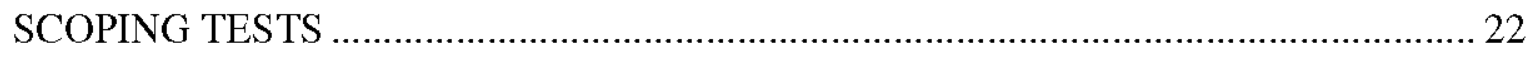

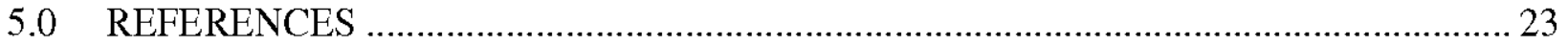

6.0 APPENDIX A: Georgia Tech Laboratory Experiment Block Flow Diagram.................... 24

7.0 APPENDIX B: Georgia Tech Laboratory Experiment Mass Balance ……........................ 25

\section{TABLE OF FIGURES}

Figure 1. Georgia Tech Scoping Tests - One-Liter Laboratory Reactor System...................... 5

Figure 2. Georgia Tech Scoping Tests - Experimental Sequence ............................................. 5

Figure 3. Georgia Tech Scoping Tests - Filter Cake Texture ………………………….......... 6

Figure 4. Georgia Tech Scoping Tests - Product Drying Results ........................................... 8

Figure 5. Georgia Tech Scoping Tests - Product Particle Size Distribution............................. 9

Figure 6. Georgia Tech Scoping Tests - XPS Analysis of Anhydrous Lithium Hydrotalcit.... 9

Figure 7. Georgia Tech Scoping Tests - Product Particle Settling Rate Test ............................ 10 
Figure 8. 222-S Laboratory Scoping Tests - Flow Chart for Preparation of Lithium Hydrotalcite

Figure 9. 222-S Laboratory Scoping Tests - Double-Shell Tank Simulant Product after Four Hours of Ripening and Unwashed Filter Cake

Figure 10. 222-S Laboratory Scoping Tests - Final Water-Washed Filter Cake from DoubleShell Tank Simulant

Figure 11. 222-S Laboratory Scoping Tests - Comparison of Aliquots of the Filtrate and Wash Filtrates from Double-Shell Tank Simulant Filter Cake. 15

Figure 12. 222-S Laboratory Scoping Tests - Back Scattered Electron Image and Energy Dispersive Spectrometry Spectrum of Double-Shell Tank Filter Cake Product 16

Figure 13. 222-S laboratory Soping Tests - Back Scattered Electron Image and Energy Dispersive Spectrometry Spectrum of Double-Shell Tank Simulant Filter Cake .... 16

Figure 14. 222-S Laboratory Scoping Tests - Single-Shell Tank Simulant Product after Two Hours of Ripening and Washed Filter Cake

Figure 15. 222-S Laboratory Scoping Tests - Comparison of Aliquots of the Filtrate and Wash Filtrates from Single-Shell Tank Simulant Filter Cake 18

Figure 16. 222-S Laboratory Scoping Tests - Back Scattered Electron Image and Energy Dispersive Spectrometry Spectrum of the Single-Shell Tank Simulant Filter Cake.

Figure 17. 222-S Laboratory Scoping Tests - Single-Shell Tank Simulant Retest Product after Four Hours of Ripening

Figure 18. Back Scattered Electron Images and Energy Dispersive Spectrometry Spectra of Single-Shell Tank Simulant Retest Filter Cake after Four Hours. 20

\section{TABLE OF TABLES}

Table 1. Georgia Tech Scoping Tests - Phase Two Product MS Analytical Results 7

Table 2. 222-S Laboratory Scoping Tests - Double-Shell Tank Simulant Chemical Makeup (1-L Batch) 13

Table 3. 222-S Laboratory Scoping Tests - Single-Shell Tank Simulant Chemical Makeup (1-L Batch) 13 


\section{LIST OF TERMS}

AFS

CTE

DST

DOE

EM

ETF

FC

HLW

ILAW

LAW

LiHT

MSE

ORP

RPP

SST

TMP

TRA

TRE

TRL

WRPS

WTP
AREVA Federal Services LLC

Critical Technology Element

Double Shell Tank

U.S. Department of Energy

Environmental Management

Effluent Treatment Facility

Fractional Crystallization

High Level Waste

Immobilized Low Activity Waste

Low Activity Waste

Lithium Hydrotalcite Precipitation

Mixed Solvent Electrolyte

Office of River Protection

River Protection Plan

Single Shell Tank

Technology Maturation Plan

Technology Readiness Assessment

Technology Readiness Evaluation

Technology Readiness Level

Washington River Protection Solutions, LLC

Waste Treatment and Immobilization Plant 
RPP-48376, Rev. 0

\subsection{INTRODUCTION}

\subsection{CONTEXT}

The U.S. Department of Energy (DOE), Office of River Protection, is constructing a Waste Treatment and Immobilization Plant (WTP) for the treatment and vitrification of the underground tank wastes stored at the Hanford site. The WTP will pre-treat the waste to separate high-level (HLW) and low-activity waste (LAW) fractions.

Aluminum is a significant fraction of the Hanford waste and is to be leached with sodium hydroxide for processing in the WTP. In order to facilitate the leaching, a large quantity of new sodium hydroxide must be added to the waste. If the sodium hydroxide or ionic strength of the waste is lowered far enough, aluminum will precipitate. While high concentrations of sodium hydroxide keep aluminum dissolved, it can also cause sodium phosphate and sodium oxalate to precipitate. Sodium is a limiting factor in the waste loading of glass; higher sodium mass creates more glass mass. Sodium hydroxide additions should be minimized whenever possible. Therefore removal of aluminum from HLW sludge is of critical importance to minimize the amount of HLW glass.

Approximately 8,710 MT of aluminum ${ }^{1}$ exists in Hanford waste. Aluminum comprises $\sim 66 \mathrm{wt} \%$ of waste sludge. Although a fraction $(\sim 30 \%)$ of the aluminum is currently soluble in waste supernatants, when cooled and diluted to $25^{\circ} \mathrm{C}$ and $5 \mathrm{M} \mathrm{Na}$ as required for WTP processing ${ }^{2}$, less than $10 \%$ remains soluble. Therefore, additional sodium hydroxide is required to dissolve and maintain the solubility of $>90 \%$ of aluminum for WTP operations. The additional amount of sodium required to dissolve and maintain aluminum solubility is approximately equal to the current sodium inventory in Hanford waste.

$$
\begin{array}{ll}
\text { Existing Na } & 48,400 \mathrm{MT} \\
\text { Required Na } & \underline{51,300 \mathrm{MT}} \\
\text { Total Na } & 99,700 \mathrm{MT}
\end{array}
$$

Thus, the increase in sodium for aluminum solubility is expected to double the total sodium in Hanford waste and increase processing time and cost proportionally. Uncertainties exist in the total inventory of sodium and aluminum, with the greatest uncertainty in the mass of existing sodium hydroxide in the waste ${ }^{3}$.

\footnotetext{
${ }^{1}$ Alumina and sodium inventories in Hanford waste is from HTWOS model run SP4 Planning Case-3.0-8.4r0-200903-30-at-20-02-39

${ }^{2} 25^{\circ} \mathrm{C}$ and $5 \mathrm{M} \mathrm{Na}$ are requirements of the Cs IX system.

${ }^{3}$ The estimate of additional sodium ( $\left.51.3 \mathrm{kMT}\right)$ is based on an existing sodium hydroxide inventory equal to $18 \%$ of total sodium. The inventory of sodium hydroxide decreases with time due to absorption of atmospheric $\mathrm{CO}_{2}$ in tank ventilation air by the reaction $2 \mathrm{NaOH}+\mathrm{CO}_{2} \rightarrow \mathrm{Na}_{2} \mathrm{CO}_{3}$
} 
To eliminate the huge sodium hydroxide demand and ease processing of aluminum sludge, AREVA has invented and patented ${ }^{4}$ the Lithium Hydrotalcite (LiHT) process for aluminum removal and sodium hydroxide regeneration from Hanford waste. The method is referred to as the "lithium hydrotalcite process" (LiHT).

As a prime contractor to the U.S. DOE, Washington River Protection Solutions, LLC (WRPS) prepares long term strategic planning options/evaluations to accomplish the mission of the River Protection Plan (RPP) including evaluation and development of supplemental pretreatment options for Hanford tank waste. The LiHT process is one option to be evaluated as a solution to create a more treatable waste for the WTP, while keeping to a minimum additional sodium hydroxide to the tank waste system.

WRPS River Protection System Plan Revision 5 (ORP-11242) includes an Aluminum Removal Facility (ARF) based on the LiHT process to reduce mission duration, minimize waste generation, and reduce costs. Recent direction from the DOE caused development of the ARF option to be discontinued and redirected work towards alternative pretreatment configurations. Even though the LiHT process was integral to the ARF, LiHT does not rely on the ARF. The ability to precipitate aluminum from Hanford waste and generate sodium hydroxide is an important chemical process that has the potential to be incorporated in alternative flow sheets that should be considered by WRPS.

Therefore, AREVA was contracted by WRPS under the "Lithium Hydrotalcite Technology Readiness Confirmation and Closure project", to assemble the documentation package for advancing the lithium hydrotalcite (LiHT) demonstration documentation and testing to the point where a Technology Readiness Assessment could be conducted.

\subsection{OBJECTIVE}

Under the direction of WRPS, the primary mission of the AREVA project team is to assess, prepare, and gather data needed to support a Department of Energy (DOE) Technology Readiness Assessment (TRA). The LiHT project was put on hold without an official readiness determination. Some prior work has not been published, and certain tests specified in the test program and data quality objectives have not been conducted. The objective of this work is to finish work that has been started and officially establish a Technology Readiness Level (TRL) for the LiHT process.

This document provides a summary of laboratory scale scoping tests that were performed in 2009 and 2010, at the Chemical Engineering Department of the Georgia Institute of Technology (Georgia Tech, RPT-3001622), and the Hanford 222-S Laboratory (LAB-RPT-10-00003), involving double-shell tank (DST) and single-shell tank (SST) waste simulants, to demonstrate the viability of the LiHT process.

\footnotetext{
${ }^{4}$ PCT International Application PCT/US2008/076589
} 
These preliminary tests set the basis for a validation testing campaign performed in 2010 (ref. 0) to demonstrate a Technology Readiness Level of 3 (ref. 0), and prepare a development plan to further mature the process utilizing different configurations of integration into the overall WTP process (ref. $0 \& 0$ ).

\subsection{TECHNOLOGY HERITAGE}

The aluminum industry uses the Bayer Process to extract aluminum oxide from bauxite ore by treating the ore with sodium hydroxide. The insoluble impurities are separated from the aluminum hydroxide solution, which is cooled, and the resulting precipitate is then filtered, and the filtered precipitate is processed to recover aluminum.

The separation and removal of the sodium aluminate contained in Hanford tank wastes using the LiHT process is a quasi analogous process in that both the ore and the aluminum compounds in the tank wastes require leaching with sodium hydroxide to solubilize the aluminum so that it can be separated from the mother liquor. Theoretically, the Bayer Process could be used to remove aluminum and regenerate sodium hydroxide from tank waste leachate. However, laboratory experiments using waste simulants experiments showed that a strict application of the Bayer Process is very slow ( $\sim 5$ days per cycle), the per-pass yield is $\sim 50 \%$, and the process would require crystal seeding and a high recycle rate to obtain optimum yield.

AFS has invented and patented a modification of the Bayer Process that overcomes the disadvantages of the application of the Bayer Process for aluminum removal from tank waste, mainly the slow pace and per-pass yield of the reaction. This alternative method is the LiHT process, which is similar to processes used in industry to produce low-cost synthetic hydrotalcites 5 .

The feed for the LiHT process is tank waste containing aqueous aluminum in the form of sodium aluminate $\left(\operatorname{NaAl}(\mathrm{OH})_{4(\mathrm{AQ})}\right)$ such as would be present in sodium hydroxide (caustic) leached tank waste sludge. A $10 \%$ aqueous solution of lithium hydroxide $(\mathrm{LiOH})$ is reacted with aqueous sodium aluminate $\left(\mathrm{NaAl}(\mathrm{OH})_{4}\right)$ and aqueous sodium carbonate $\left(\mathrm{Na}_{2} \mathrm{CO}_{3}\right)$, a common constituent of tank waste, which is also present in the tank waste stream, to produce solid lithium hydrotalcite $\mathrm{Li}_{2} \mathrm{CO}_{3} \cdot 4 \mathrm{Al}(\mathrm{OH})_{3} \cdot 3 \mathrm{H}_{2} \mathrm{O}$, and to simultaneously generate aqueous sodium hydroxide according to the reaction:

$$
2 \mathrm{LiOH}_{(A Q)}+4 \mathrm{NaAl}(\mathrm{OH})_{4(A Q)}+\mathrm{Na}_{2} \mathrm{CO}_{3(A Q)}+3 \mathrm{H}_{2} \mathrm{O} \rightarrow \mathrm{Li}_{2} \mathrm{CO}_{3} \cdot 4 \mathrm{Al}(\mathrm{OH})_{3} .3 \mathrm{H}_{2} \mathrm{O}_{(S)}+6 \mathrm{NaOH}_{(A Q)}
$$

${ }^{5}$ Handbook of Clay Science, F. Bergaya, p. 1027 
The solid lithium hydrotalcite (LiHT) can be easily separated by filtration from the mother liquor (aluminum depleted supernatant), thus removing aluminum from the waste treatment system and generating sodium hydroxide. The sodium hydroxide produced is then available to be recycled to leach additional aluminum containing sludge according to the reaction:

$$
\mathrm{NaOH}+\mathrm{Al}(\mathrm{OH})_{3(S)} \rightarrow \mathrm{NaAl}(\mathrm{OH})_{4(A Q)}
$$

The recovered lithium hydrotalcite is water-washed to remove cesium contamination, and dried. It can then be disposed of as a Low Level Waste, or if this is not possible, used as a WTP LAW glass former.

\subsection{SCOPING TESTS PERFORMED AT THE GEORGIA TECH LABORATORY}

\subsection{PURPOSE}

To demonstrate the viability of the hydrotalcite precipitation process, a two-phase laboratory program was conducted at the Chemical Engineering Department of the Georgia Institute of Technology (Georgia Tech) in 2009.

Georgia Tech was selected because of prior experience with fractional crystallization of sodium salts in simulated SST and DST wastes.

\subsection{TEST CONFIGURATION}

Phase 1 experiments were designed to test the temperature and $\mathrm{pH}$ ranges of the LiHT precipitation reaction.

The Phase 2 experimental matrix was designed to test the sensitivity of the Li/Al mole ratio, the lithium reagent $\left(\mathrm{LiNO}_{3} \& \mathrm{LiOH}\right)$, the reaction period, solid/liquid separability, and the amount of wash water for cesium decontamination.

The reactions were conducted near the boiling point of the solution $\left(\sim 100^{\circ} \mathrm{C}\right)$ where aluminum has the highest solubility in caustic solution at atmospheric pressure. The separations were done at $60^{\circ} \mathrm{C}$.

The experimental apparatus used for hydrotalcite precipitation was a 1-liter jacketed reactor system with a motor-driven agitator (Chemglass CG-950-18). A diagram of the apparatus is shown in Figure 1.

After precipitation, the slurries were filtered and washed using a Buchner funnel with $0.45 \mu \mathrm{m}$ PVDF Millipore Dura pore filter paper.

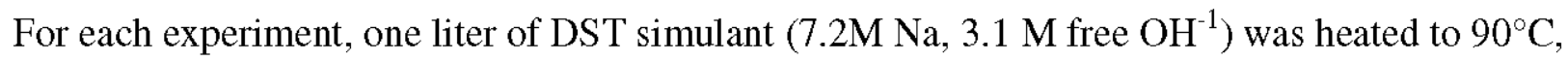
then fortified with solid $\mathrm{Al}(\mathrm{OH})_{3}$ to simulate heat leaching of aluminum containing sludge to saturation into hot supernatant (Photo A). A total of 128 grams/liter of aluminum (1.6 M Al) were heat leached into the DST simulant using native free hydroxide. In these experiments, 
lithium hydroxide or nitrate was used as the reagent. A total of 19.5 grams of lithium hydroxide or 56.1 grams of lithium nitrate $(0.8 \mathrm{M} \mathrm{Li})$ were added as saturated, aqueous solutions.

A flow sheet and mass balance of an experimental run are shown in Appendices A and B in sections 6.0 and 7.0 .

Figure 1. Georgia Tech Scoping Tests - One-Liter Laboratory Reactor System

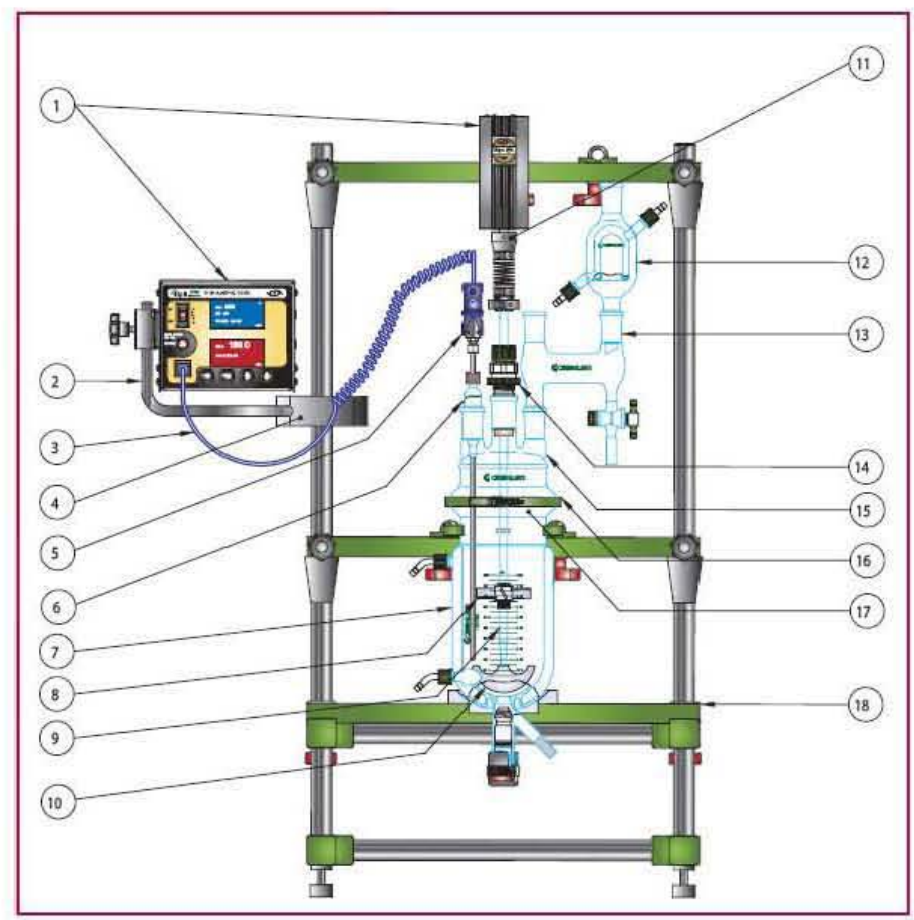

\subsection{TESTS RESULTS}

Nucleation and growth of lithium hydrotalcite was spontaneous and slightly exothermic $(\Delta \mathrm{T}=$ $5^{\circ} \mathrm{C}$ ), as indicated by suspended solids (Photo B, Figure 2), and temperature rise. Precipitation yield of aluminum was near the theoretical yield (97\%) in less than one hour.

The product slurry ( $18 \mathrm{wt} \%$ solids) was free-flowing. The slurry was deliquored and washed in a Büchner funnel (Photo C, Figure 2). Permeability of the filter cake was good and the cake deliquored and washed rapidly $(\sim 100 \mathrm{ml} / \mathrm{min})$. Within 10 minutes, the cake was drained of free liquid. From microscopic imaging, crystallite size was $(\sim 1 \mu \mathrm{m})$, particle diameter was approximately $50 \mu \mathrm{m}$ and cake interstitial liquid content was approximately $50 \%$. The filter cake was water washed ${ }^{6}$ with two 1-liter volumes of deionized (DI) water (Photo D, Figure 2). Based upon the residual chromium (yellow) color of the cake and spent wash, decontamination was visually determined complete after 2 liters of wash water were applied to the product cake (Photo E, Figure 2). After cooling to ambient temperature and settling for one day, the filtrate did not produce settled solids. The lack of solids in the filtrate indicated that precipitation reaction was complete before filtration.

\footnotetext{
${ }^{6}$ Because the product is insoluble in water, a saturated (salt containing) wash solution is not needed.
} 
Figure 2. Georgia Tech Scoping Tests - Experimental Sequence
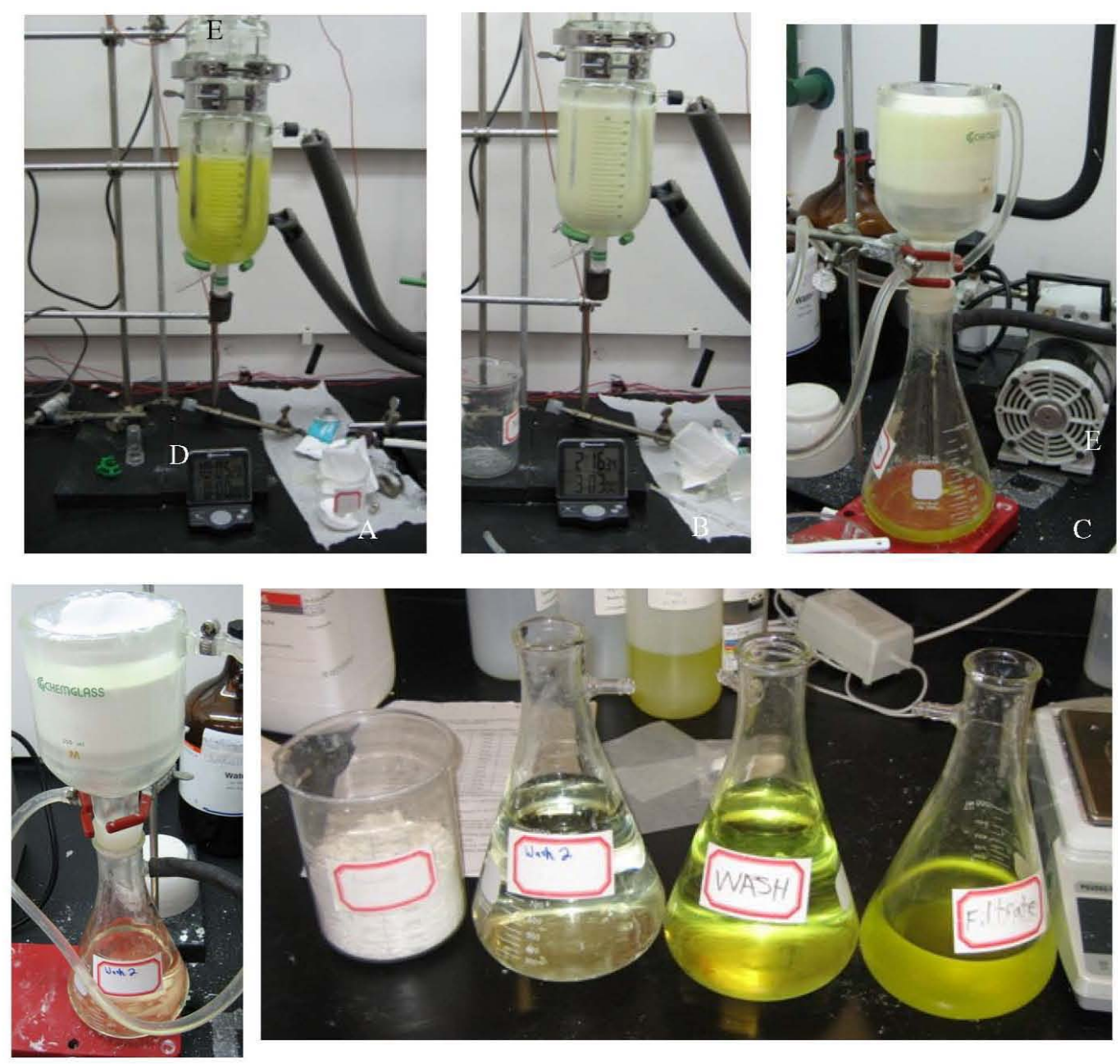

Although the product filtered rapidly, the filter cake texture resembled soft clay (Figure 3). The product was oven-dried at $90^{\circ} \mathrm{C}$ to remove residual filter cake moisture. The dried product is a free-flowing, hygroscopic bright white powder. Samples of the solids were analyzed elementally by ICP-MS.

Figure 3. Georgia Tech Scoping Tests - Filter Cake Texture

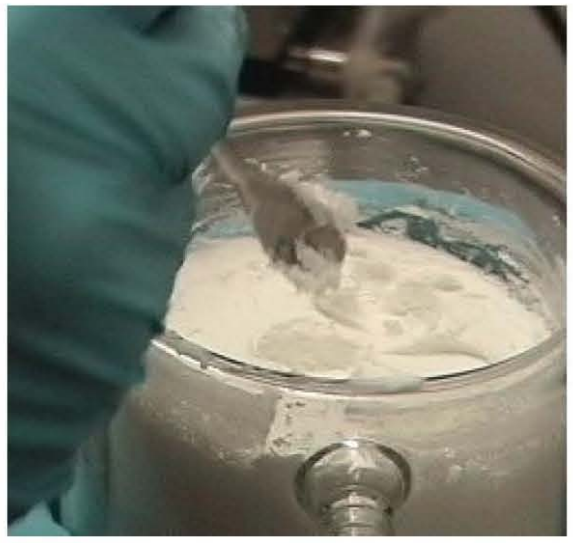


Mass Spectrometry (MS) analytical results of the product from the Phase 2 experimental runs are shown in Table 1.

Table 1. Georgia Tech Scoping Tests - Phase Two Product MS Analytical Results

\begin{tabular}{|l|r|r|r|r|r|}
\hline SAMPLE \# & & 2 & 6 & 9 & 11 \\
\hline RUN \# & & 1 & 2 & 3 & \multicolumn{1}{c|}{3} \\
\hline FEED Li/Al & & 1 & 0.5 & 0.5 & 0.5 \\
\hline WASHES & & \multicolumn{1}{|c|}{2} & 2 & \multicolumn{1}{c|}{2} & \multicolumn{1}{c|}{4} \\
\hline & $\mathrm{MW}$ & $\mathrm{mg} / \mathrm{kg}$ & $\mathrm{mg} / \mathrm{kg}$ & $\mathrm{mg} / \mathrm{kg}$ & $\mathrm{mg} / \mathrm{kg}$ \\
\hline & & & & & \\
\hline $\mathrm{Cl}$ & 35.45 & 85 & 150 & 150 & 7.8 \\
\hline $\mathrm{N}$ & 14.01 & 740 & 620 & 1,000 & 28 \\
\hline $\mathrm{Al}$ & 26.89 & 320,000 & 460,000 & 490,000 & 340,000 \\
\hline $\mathrm{Cs} *$ & 132.91 & 0.37 & 0.65 & 0.74 & 0.085 \\
\hline $\mathrm{Li}$ & 6.94 & 35,000 & 52,000 & 54,000 & 36,000 \\
\hline $\mathrm{Na}$ & 22.99 & 5,200 & 11,000 & 14,000 & 1,300 \\
\hline & & & & & \\
\hline TOTAL & & 361,025 & 523,771 & 559,151 & 377,336 \\
\hline & & & & & \\
\hline $\mathrm{Li} / \mathrm{Al}$ & & 0.424 & 0.438 & 0.427 & 0.410 \\
\hline $\mathrm{Cs} \mathrm{DF}$ & & 461 & 377 & 353 & 2,131 \\
\hline $\mathrm{Na}$ DF & & 457 & 310 & 260 & 1,941 \\
\hline $\mathrm{Cs} \mathrm{Ci} / \mathrm{m} 3$ & & 40 & 71 & 81 & 9 \\
\hline
\end{tabular}

*Below quantitation limit

In each case, the $\mathrm{Li} / \mathrm{Al}$ atomic ratio in the product averaged 0.42 . Thus, increasing feed lithium above stoichiometric $(1: 2 \mathrm{Li} / \mathrm{Al})$ as in Run 1 does not increase lithium in the product.

There appears to be no direct correlation between run time and product quality. Run \#3 was done rapidly ( $\mathrm{LiOH}$ addition $<30$ minutes), however the product filtered and decontaminated rapidly, and the yield was equivalent to the other runs. This result indicates that the reaction rate at $90^{\circ} \mathrm{C}$ is rapid and long retention time is not necessary to complete the reaction.

Although cesium measurements were below the analytical quantification limit, the cesium decontamination factor (DF) was equivalent to the sodium DF in all cases. Both Na and Cs DF's were very high (DF 2,000) after four 1 liter washes. This result indicates $\mathrm{Cs}$ and $\mathrm{Na}$ are not being measurably included in the hydrotalcite crystal structure and are removed from cake interstitial liquor by water washing ${ }^{7}$. Thus, the extent of decontamination is in direct proportion to the amount of volume of wash water ${ }^{8}$.

Based on a ${ }^{137} \mathrm{Cs} /{ }^{133} \mathrm{Cs}$ ratio of 0.5 (typical for Hanford DST waste), total radioactivity ranges from 9 to $81 \mathrm{Ci} / \mathrm{m}^{3}$ in the product. At the highest value, this loading is $1.7 \%$ of the Class $\mathrm{C}$ disposal limit $\left(4,600 \mathrm{Ci} / \mathrm{m}^{3}\right)^{9}$. In addition, the dried product is hygroscopic and has low leach

\footnotetext{
${ }^{7}$ It is believed that both ions are displaced from the product equivalently, sodium may be used as a surrogate for estimating the extent of cesium decontamination when cesium is below the quantitation limit.

${ }^{8}$ The extent of decontamination may be estimated by the formula $D=1-\left(1 /(1+\mathrm{W} / \mathrm{L})^{\mathrm{n}}\right)$ where $\mathrm{W}=$ wash mass, $\mathrm{L}=$ interstitial liquor mass, and $\mathrm{n}=$ number of washes.

${ }^{9}$ 10CFR 61.55
} 
ability. By these preliminary observations, the product should be suitable for land disposal as Class C LLW.

Product drying results are shown in Figure 4.

Figure 4. Georgia Tech Scoping Tests - Product Drying Results

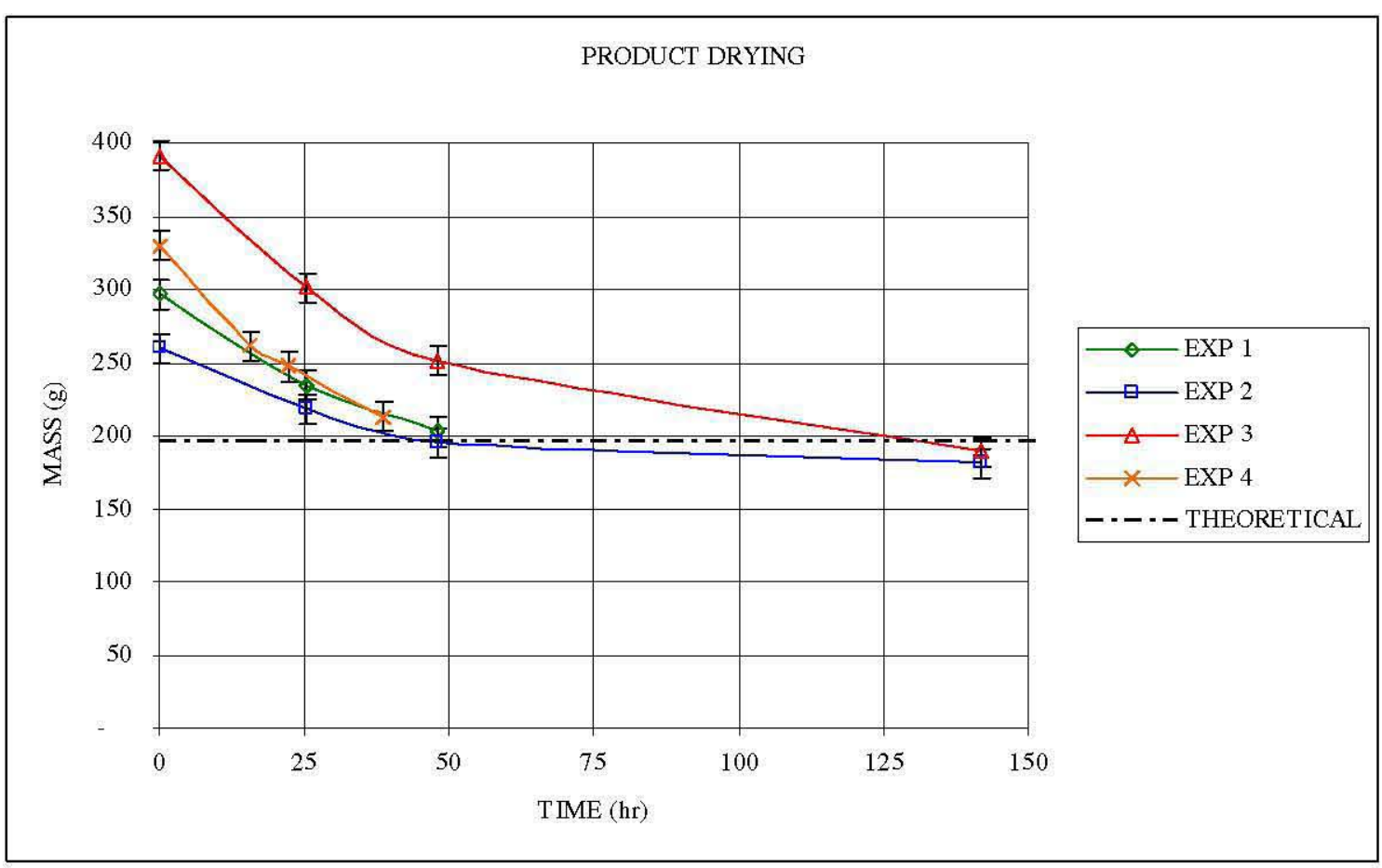

The products were dried in an oven at $90^{\circ} \mathrm{C}$ for several days to remove interstitial moisture. Although there was a wide variation in initial wet cake mass (260 to $390 \mathrm{~g}$ ), the final dried masses were within $93 \%$ of the theoretical yield. Principal yield loss was due to solid accumulation in the reactor vessel.

Particle size distribution for Run \#1 is shown in Figure 10. Mass-averaged particle size was $50 \mu \mathrm{m}$, with few $(0.43 \%)$ particles below $5 \mu \mathrm{m}$. The narrow size distribution of the product improves solid/liquid separation because the open pore size between particles is uniform and allows high liquid permeability. 
Figure 5. Georgia Tech Scoping Tests - Product Particle Size Distribution

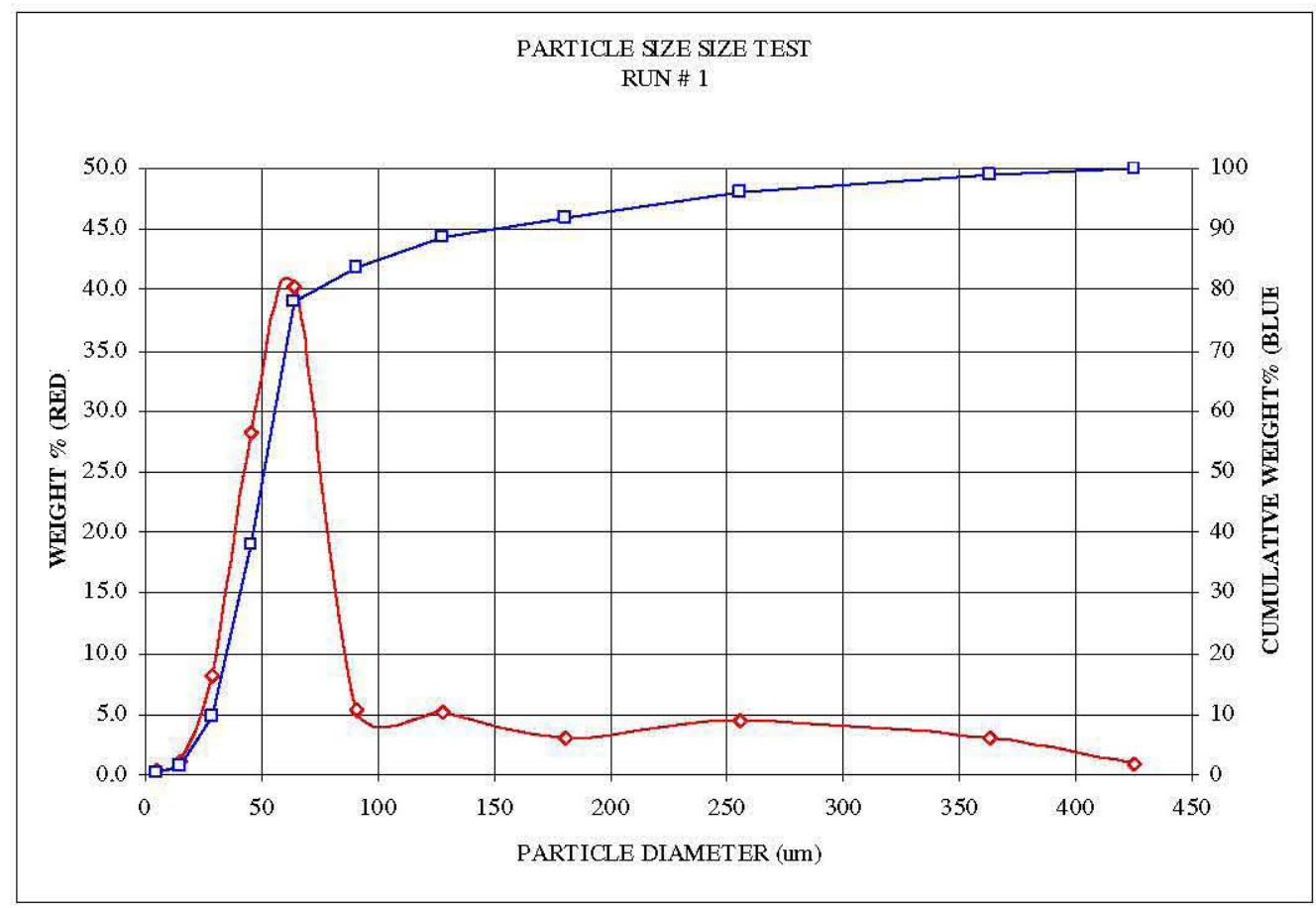

An X-ray Photoelectron Spectroscopy (XPS) analysis of a dried filter cake is shown in Figure 6. The survey spectrum was obtained on a $400 \mu \mathrm{m}$ spot size.

Figure 6. Georgia Tech Scoping Tests - XPS Analysis of Anhydrous Lithium Hydrotalcit.

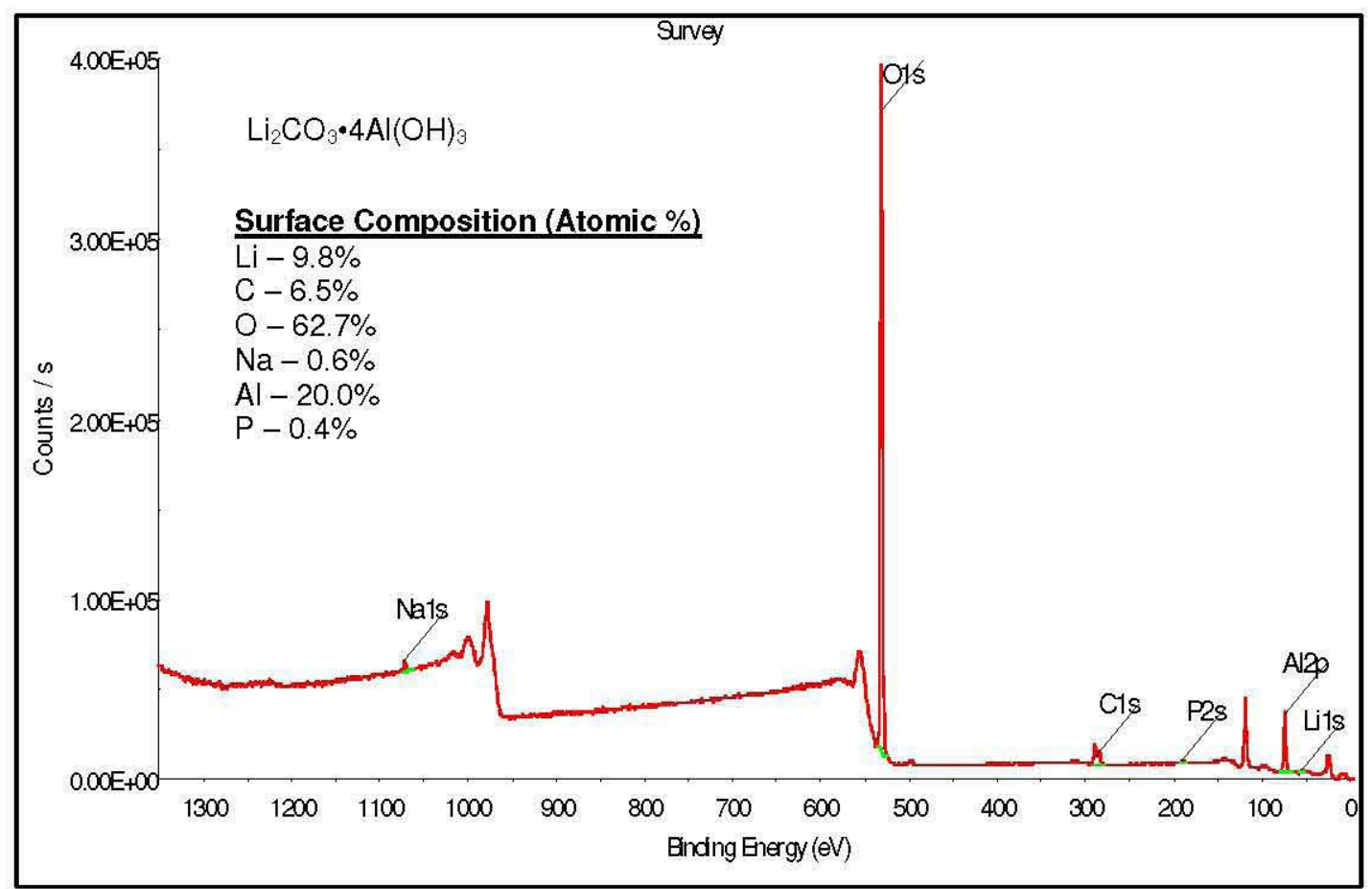


The XPS analysis identified the dried product as anhydrous Lithium Hydrotalcite $\left(\mathrm{Li}_{2} \mathrm{CO}_{3} \cdot 4 \mathrm{Al}(\mathrm{OH})_{3}\right)$. The XPS survey indicated that the major surface elements were lithium, carbon, oxygen, and aluminum. In addition, low amounts of sodium and phosphorous were detected. The surface concentrations (atomic \%) of the detected elements are very close to the theoretical values (ignoning hydrogen, which cannot be detected by XPS).

A high resolution XPS survey showed the presence of carbon ate as well as some hydrocarbon contamin ation, which is unawoid able in XPS. The observed binding energies for the major elements (i.e. $\mathrm{Li}, \mathrm{Al}, \mathrm{O}$ ) were con sistent with $\mathrm{Li}_{2} \mathrm{CO}_{3}$ and $\mathrm{Al}(\mathrm{OH})_{3}$ species. The observed binding energies ( $\mathrm{P} 2 \mathrm{P}$ and $\mathrm{P} 2 \mathrm{~s}$ ) were characteristic of phosphate type species.

Particle settling tests were performed to estimate aperage settling rate of the solids in deionized water (see Figure 7). Average particle settling rate was measured at 2 to 3 inchesiminute. The settling rate is rapid compared to gibbsite particles ( $<$ inch/hour). This result indicates that product decontamination may be performed by batch settling or oontinuous elutriation (countercunent washing), and that batch decontamination may be done by a series of mixingsettling-decanting steps in a mixed pessel to disperse, separate and remove spent wash liquor, and decontamin ate the product from water-soluble impurities.

Figure 7. Georgia Tech Scoping Tests - Product Parbicle Settling Rate Test

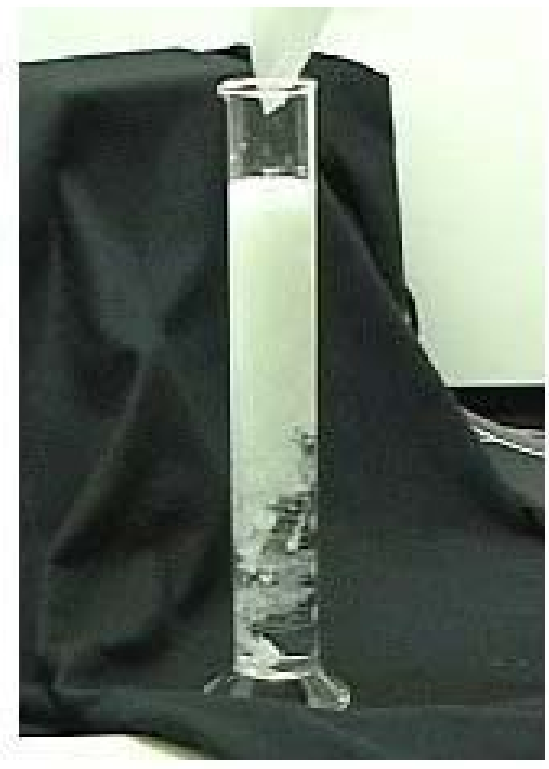




\subsection{CONCLUSIONS}

From experimental results, it may be concluded that aqueous sodium aluminate can be rapidly precipitated, separated, and decontaminated in high yield from simulated DST liquor by the formation of lithium hydrotalcite. The dried product is suitable for Class C disposal or may be used as a LAW glass former. The hydroxide-rich filtrate may be recycled to leach additional aluminum sludge or fed-forward to WTP for final treatment.

The tests determined that high aluminum yield $(>93 \%)$ was obtained at high temperature $\left(100^{\circ} \mathrm{C}\right)$ and high $\mathrm{pH}(>14)$ and that cooling and/or carbonation did not enhance yield. From those results, it was concluded that the reaction can be performed directly in concentrated caustic waste without dilution or partial neutralization, and at elevated temperature to maximize aluminum yield. Also, carbonate does not limit yield; other anions (e.g. $\mathrm{NO}_{3}{ }^{-1}, \mathrm{NO}_{2}{ }^{-1}$ ) may substitute in a carbonate depleted system. Yield loss was primarily due to solid accumulation in the reactor.

\subsection{SCOPING TESTS PERFORMED AT THE 222-S LABORATORY}

\subsection{PURPOSE}

The 222-S Laboratory at US Department of Energy Hanford Site was tasked to verify the precipitation of aluminum using lithium hydroxide as proposed by AFS. Recent industrial applications of this process were aimed toward producing nano-scale surface layers or to use hydrotalcites as drug delivery systems; therefore, although the chemistry of lithium hydrotalcite is well studied, reaction conditions in the literature are not directly adaptable to the removal of aluminum from tank waste.

To challenge the process, two Hanford tank simulants were used: one representing DST chemistry, and one representing SST chemistry. The tests were primarily designed to qualitatively verify the process potential for the Hanford WTP, and to identify the areas of improvement.

\subsection{TEST CONFIGURATION}

The tests were conducted to include each step of the proposed LiHT process, including gibbsite leaching, LiHT precipitation, crystal ripening at $90^{\circ} \mathrm{C}$ (for 4 hours), filtration, and final wash steps.

The test were performed in a glass beaker on a hot plate with a stir bar and thermocouple temperature controller. The filter cake was extracted from the solution using a Buchner funnel with $0.7 \mu \mathrm{m}$ glass fiber filter.

The DST simulant was prepared in a 5-M sodium version, as prescribed in CH2M-0403873, Preparation of Simulated Waste Samples for EM-21 Project. 
The SST simulant was prepared with the original sodium molarity $(8.5 \mathrm{M})$, to identify the boundaries of the process in terms of ionic strength and saturation of some anions.

The chemical makeup for the DST and SST simulants is presented in Table 2 and Table 3.

Figure 8. 222-S Laboratory Scoping Tests - Flow Chart for Preparation of Lithium Hydrotalcite

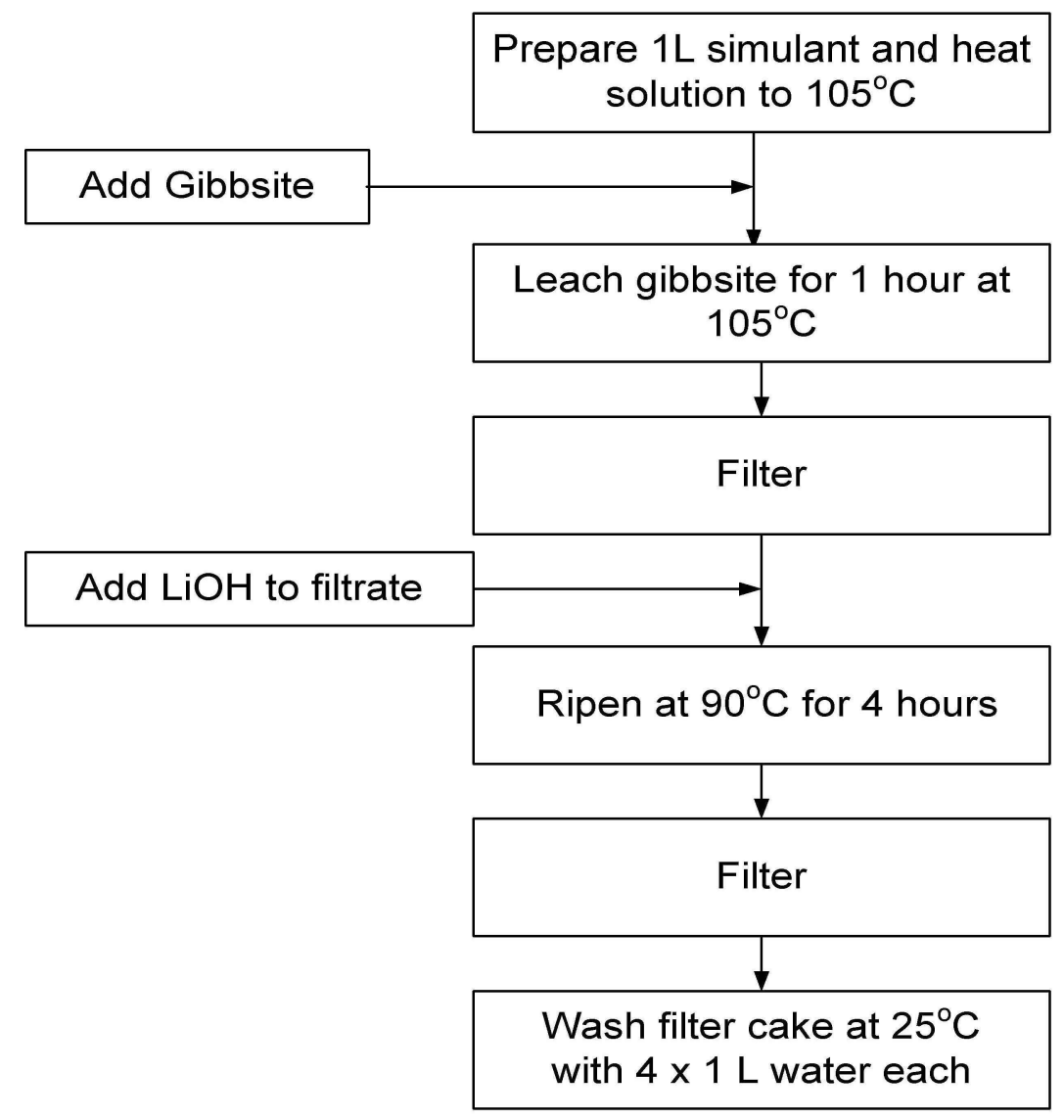


Table 2. 222-S Laboratory Scoping Tests - Double-Shell Tank Simulant Chemical Makeup (1-L Batch)

\begin{tabular}{|l|c|c|c|}
\hline \multicolumn{1}{|c|}{ Reagent } & MW & Weight [g] & Amount [mol] \\
\hline $\mathrm{NaOH}$ & 40.0 & 103.63 & 2.59 \\
\hline $\mathrm{Na}_{2} \mathrm{CO}_{3}$ & 106.0 & 6.81 & 0.06 \\
\hline $\mathrm{Na}_{2} \mathrm{C}_{2} \mathrm{O}_{4}$ & 134.0 & 0.039 & 0.0003 \\
\hline $\mathrm{KNO}_{3}$ & 101.0 & 19.64 & 0.19 \\
\hline $\mathrm{NaNO}_{3}$ & 85.0 & 77.74 & 0.91 \\
\hline $\mathrm{NaNO}_{2}$ & 69.0 & 79.51 & 1.15 \\
\hline $\mathrm{Na}_{2} \mathrm{SO}_{4}$ & 142.0 & 1.02 & 0.007 \\
\hline $\mathrm{Na}_{3} \mathrm{PO}_{4} \cdot 12 \mathrm{H}_{2} \mathrm{O} \cdot 0.25 \mathrm{NaOH}$ & 390.1 & 2.81 & 0.007 \\
\hline $\mathrm{NaCl}$ & 58.4 & 6.73 & 0.12 \\
\hline $\mathrm{NaF}$ & 42.0 & 0.45 & 0.01 \\
\hline $\mathrm{Na}_{2} \mathrm{Cr}_{2} \mathrm{O}_{7} \cdot 2 \mathrm{H}_{2} \mathrm{O}$ & 298.0 & 0.43 & 0.001 \\
\hline $\mathrm{NaC}_{2} \mathrm{H}_{3} \mathrm{O}_{2} \cdot 3 \mathrm{H}_{2} \mathrm{O}$ & 136.1 & 5.44 & 0.04 \\
\hline $\mathrm{CsNO}_{3}{ }^{2}$ & 211 & 0.101 & 0.0005 \\
\hline $\mathrm{Al}_{(\mathrm{OH})_{3}}{ }^{b}$ & 78 & 62.4 & 0.80 \\
\hline
\end{tabular}

a Cs-nitrate was added as an aqueous solution of $210 \mathrm{mg}$ Cs-nitrate salt in $250 \mathrm{~mL}$ water.

${ }^{\mathrm{b}}$ Gibbsite was heat leached into the solution at $105^{\circ} \mathrm{C}$ for 1 hour.

Table 3. 222-S Laboratory Scoping Tests - Single-Shell Tank Simulant Chemical Makeup (1-L Batch)

\begin{tabular}{|l|c|c|c|}
\hline \multicolumn{1}{|c|}{ Reagent } & MW & $\begin{array}{c}\text { Weight } \\
{[\mathbf{g}]}\end{array}$ & Amount [mol] \\
\hline $\mathrm{NaOH}$ & 40.0 & 85.27 & 2.13 \\
\hline $\mathrm{Na}_{2} \mathrm{CO}_{3}$ & 106.0 & 61.48 & 0.58 \\
\hline $\mathrm{Na}_{2} \mathrm{C}_{2} \mathrm{O}_{4}$ & 134.0 & 1.34 & 0.01 \\
\hline $\mathrm{KNO}_{3}$ & 101.0 & 3.03 & 0.03 \\
\hline $\mathrm{NaNO}_{3}$ & 85.0 & 328.95 & 3.87 \\
\hline $\mathrm{NaNO}_{2}$ & 69.0 & 56.58 & 0.82 \\
\hline $\mathrm{Na}_{2} \mathrm{SO}_{4}$ & 142.0 & 19.88 & 0.14 \\
\hline $\mathrm{Na}_{3} \mathrm{PO}_{4} \cdot 12 \mathrm{H}_{2} \mathrm{O} \cdot 0.25 \mathrm{NaOH}$ & 390.1 & 15.60 & 0.04 \\
\hline $\mathrm{NaCl}$ & 58.4 & 4.67 & 0.08 \\
\hline $\mathrm{NaF}^{\mathrm{Na}} \mathrm{Cr}_{2} \mathrm{O}_{7} \cdot 2 \mathrm{H}_{2} \mathrm{O}$ & 42.0 & 0.63 & 0.02 \\
\hline $\mathrm{CsNO}{ }_{3}{ }^{a}$ & 298.0 & 11.92 & 0.04 \\
\hline $\mathrm{Al}\left(\mathrm{OH}_{3}{ }_{3}{ }^{\mathrm{b}}\right.$ & 211.0 & 0.021 & 0.0001 \\
\hline
\end{tabular}

${ }^{a}$ Cs-nitrate was added as an aqueous solution of $210 \mathrm{mg}$ Cs-nitrate salt in $250 \mathrm{~mL}$ water.

${ }^{\mathrm{b}}$ Gibbsite was heat leached into the solution at $105^{\circ} \mathrm{C}$ for 1 hour. 
Samples for chemical analyses were taken from an aliquot of wash water of each of the four washing steps, as well as from an aliquot of the filter cake. All samples were submitted to Advanced Technologies and Laboratories, Intl. (ATL) for analyses on $\mathrm{Li}, \mathrm{Al}, \mathrm{Cs}, \mathrm{P}, \mathrm{S}$, anions, total inorganic carbon/total organic carbon (TIC/TOC), free hydroxide, and percent water (using, e.g., inductively coupled plasma-atomic emission spectroscopy (ICP-AES), inductively coupled plasma-mass spectroscopy (ICP-MS), Ion Chromatography (IC), and thermal gravimetric analysis (TGA)). From the remaining filter cake, samples were taken for physical characterization using polarized light microscopy (PLM), scanning electron microscopy (SEM), and X-ray diffraction (XRD).

The SST simulant was prepared in the same way as the DST simulant, accounting for the formulation differences. The test was run according to the flow chart in Figure 8. After addition of $6.79 \mathrm{~g}$ of Li-hydroxide $(0.16 \mathrm{~mol})$, the solution was kept at $90{ }^{\circ} \mathrm{C}$. Due to time constraints, filtration was performed after 2 hours of ripening (instead of 4 hours as in the DST test) and produced $850 \mathrm{~mL}$ of filtrate. For each water wash, $850 \mathrm{~mL}$ D.I. water (1:1 ratio of filtrate to wash water) was used.

\subsection{TESTS RESULTS}

\subsubsection{Double Shell Tank Simulant}

Rapid addition of Li-hydroxide caused a reaction in less than 2 minutes with white particulate flocculating in the beaker. During the 4 hours of crystal ripening at $90^{\circ} \mathrm{C}$, the solution turned milky white (see Figure 9). The solution filtered quickly ( $1 \mathrm{~min}$ ) and produced an off-white filter cake. Four washing steps of the filter cake produced a bright white fluffy product of highly crystalline material (see Figure 10).

The wash processes released most of the water soluble ions in the first water wash as shown on Figure 11. Analysis showed that after the $1^{\text {st }}$ water wash, $<1 \mathrm{~mol} \%$ of the removable ions were left on the filter cake. The filtrate was clear and showed no visible signs of unfiltered solids.

Figure 9. 222-S Laboratory Scoping Tests - Double-Shell Tank Simulant Product after Four Hours of Ripening and Unwashed Filter Cake
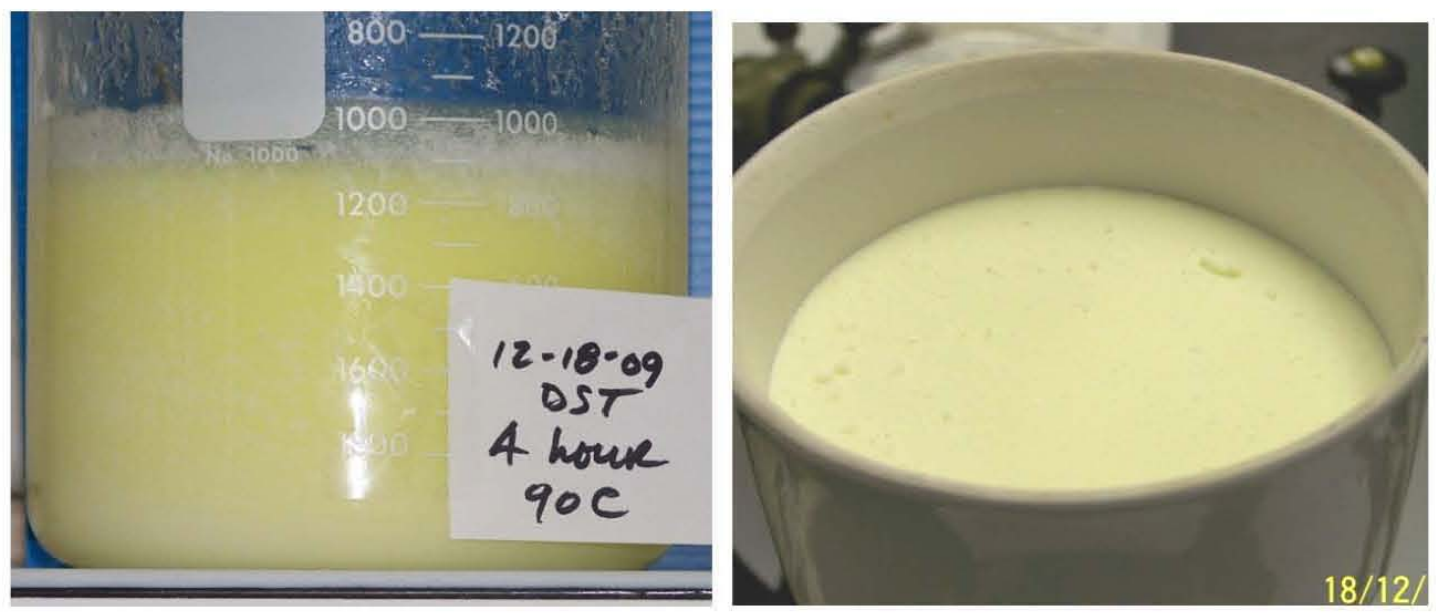
Figure 10. 222-S Laboratory Scoping Tests - Final Water-Washed Filter Cake from Double-Shell Tank Simulant

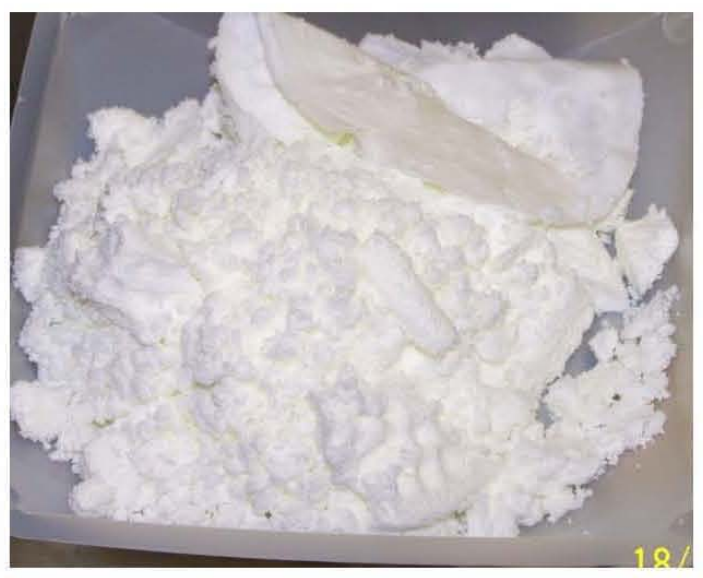

Figure 11. 222-S Laboratory Scoping Tests - Comparison of Aliquots of the Filtrate and Wash Filtrates from Double-Shell Tank Simulant Filter Cake

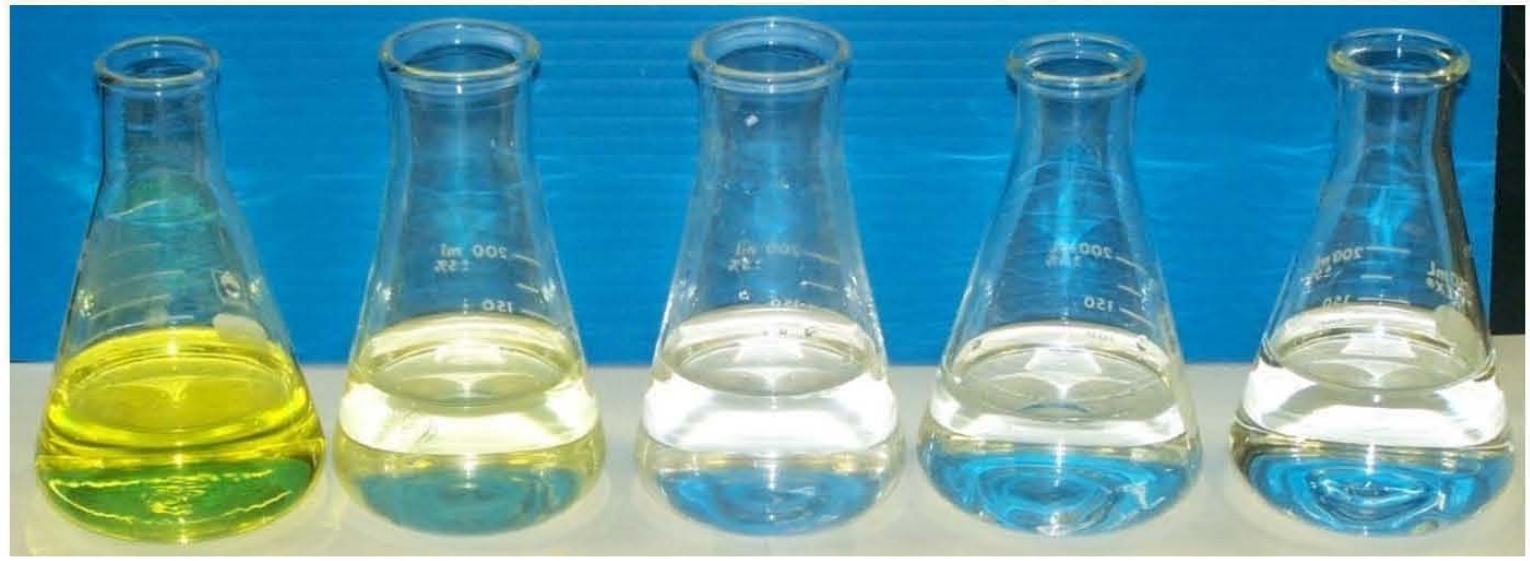

(left to right: filtrate after 4 hours reaction time, $1^{\text {st }}$ to $4^{\text {th }}$ water wash)

Typical agglomerates found in the DST LiHT product are displayed in the Back Scattered Electron (BSE) images of Figure 12 and Figure 13. The agglomerates reach about $50 \mu \mathrm{m}$ in diameter and are made of very thin platelets $(\sim 1 \mu \mathrm{m})$ of about 5-10 $\mu \mathrm{m}$ diameter. 
Figure 12. 222-S Laboratory Scoping Tests - Back Scattered Electron Image and Energy Dispersive Spectrometry Spectrum of Double-Shell Tank Filter Cake Product
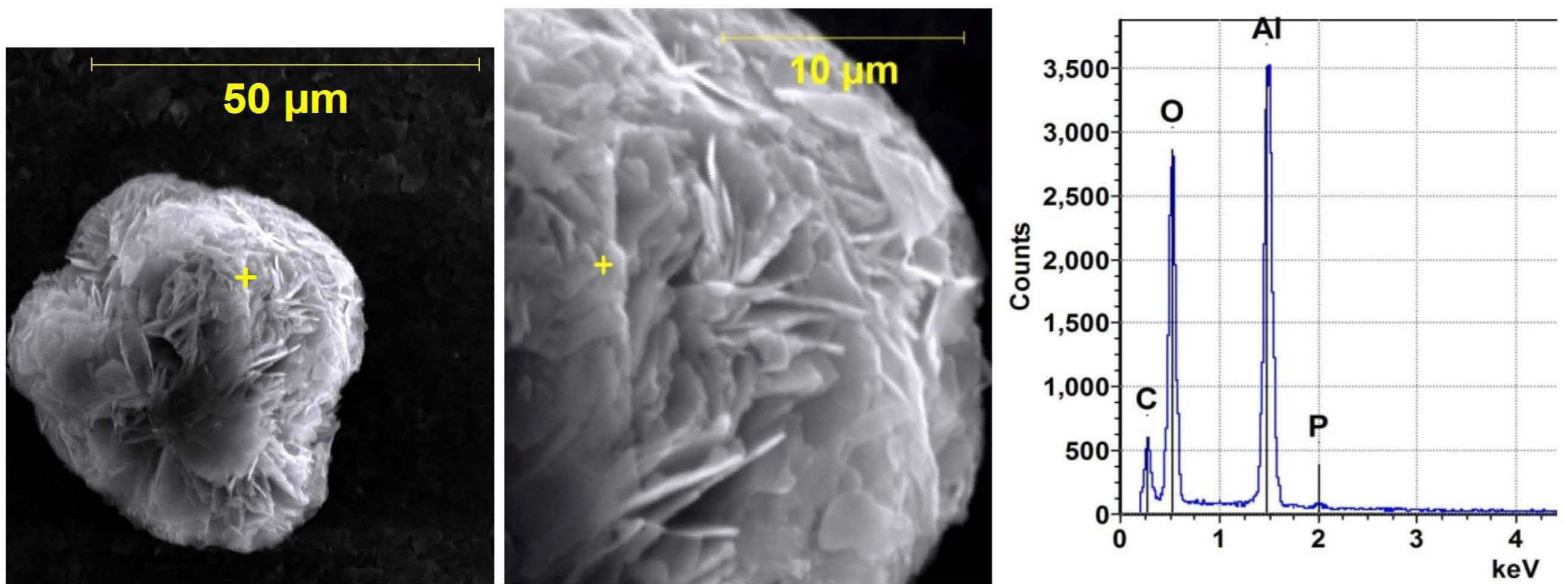

Figure 13. 222-S laboratory Soping Tests - Back Scattered Electron Image and Energy Dispersive Spectrometry Spectrum of Double-Shell Tank Simulant Filter Cake
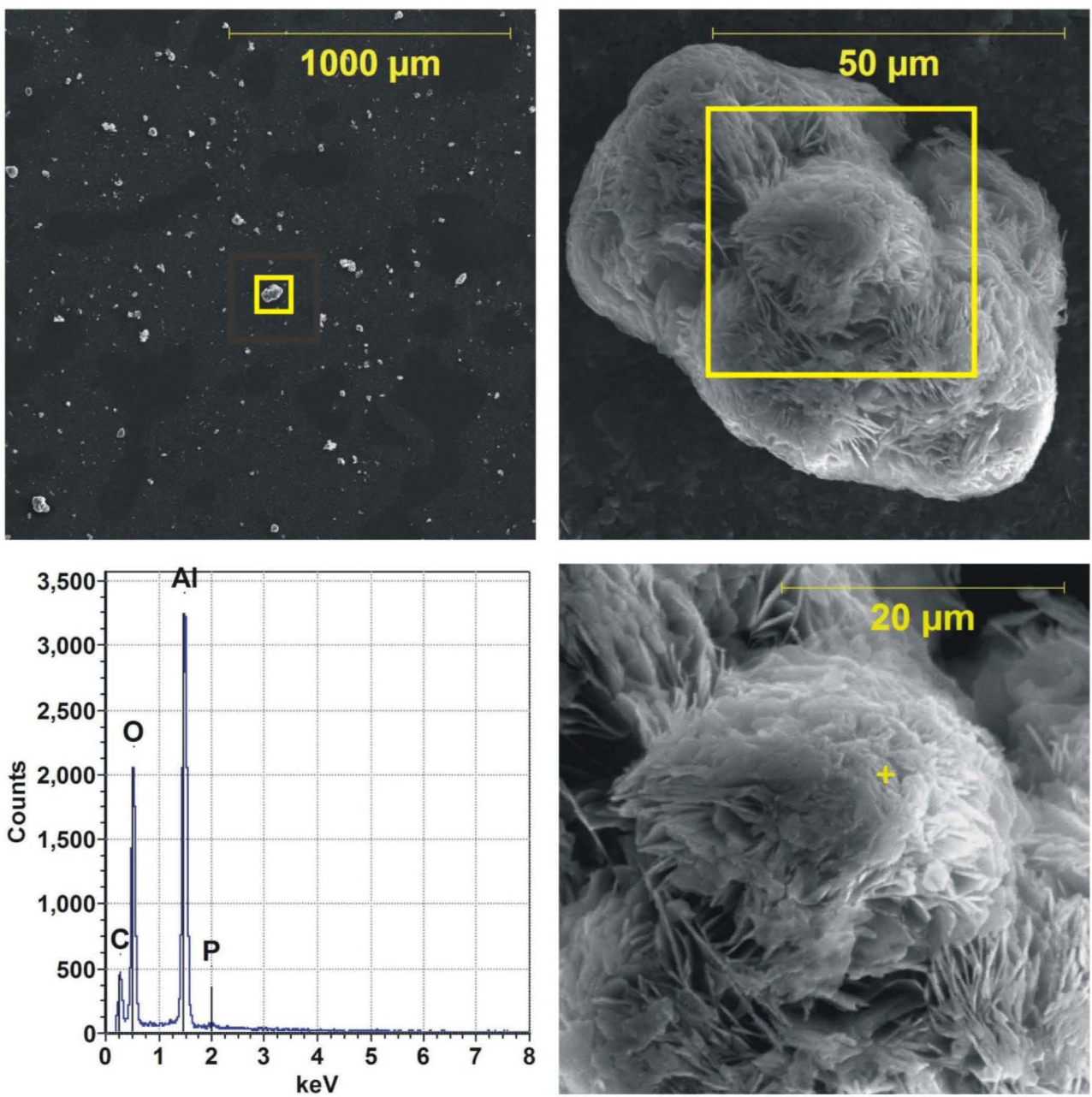

An XRD spectrum analysis showed that the filter cake is entirely made of Li-hydrotalcite in the carbonate form. Only traces of sodium nitrate $\left(\mathrm{NaNO}_{3}\right)$ were found as an additional phase. 


\subsubsection{Single Shell Tank Simulant}

\subsubsection{First SST Run}

After Li-hydroxide addition, an instantaneous reaction was observed with a white product flocculating in the beaker. Within 1 minute, the beaker was entirely opaque. Over the next 2 hours of crystal ripening, the general appearance did not change much. The product after 2 hours of crystal ripening is shown in Figure 14.

\section{Figure 14. 222-S Laboratory Scoping Tests - Single-Shell Tank Simulant Product after Two Hours of Ripening and Washed Filter Cake}
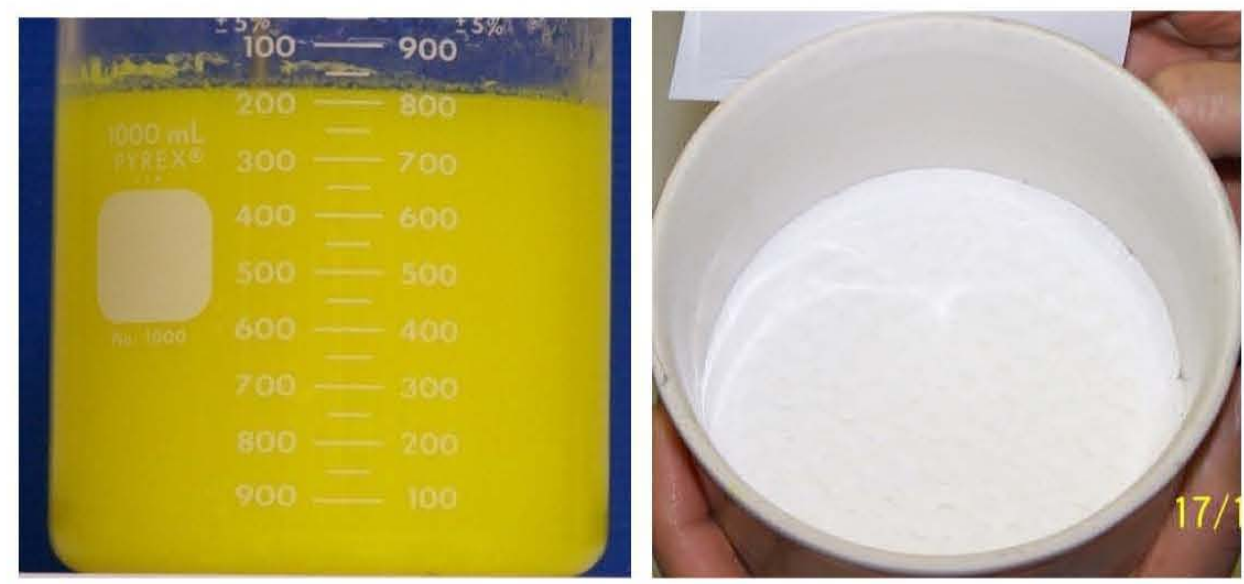

The washed filter cake consisted of white crystals. The product filtered quickly and produced an optically very clear filtrate.

Figure 15 shows Erlenmeyer flasks with an aliquot of the filtrate and the four water washes. The extreme color change between filtrate, wash water 1 , and wash water 2 indicates that most of the $\mathrm{Cr}$ is washed out in the first step. As with the DST product, the wash processes released most of the water soluble ions in the first water wash. Analysis showed that most of the nitrate, nitrite, hydroxide sulfur, cesium, and most of the carbonate were found in the filtrate. Lithium formed $\mathrm{Li}_{3} \mathrm{PO}_{4}$, as determined by XRD, but not to completion. Only $\sim 87 \mathrm{~mol} \%$ of the available $\mathrm{Li}$ precipitated, of which $10 \mathrm{~mol} \%$ were water soluble during the washes. 
Figure 15. 222-S Laboratory Scoping Tests - Comparison of Aliquots of the Filtrate and Wash Filtrates from Single-Shell Tank Simulant Filter Cake

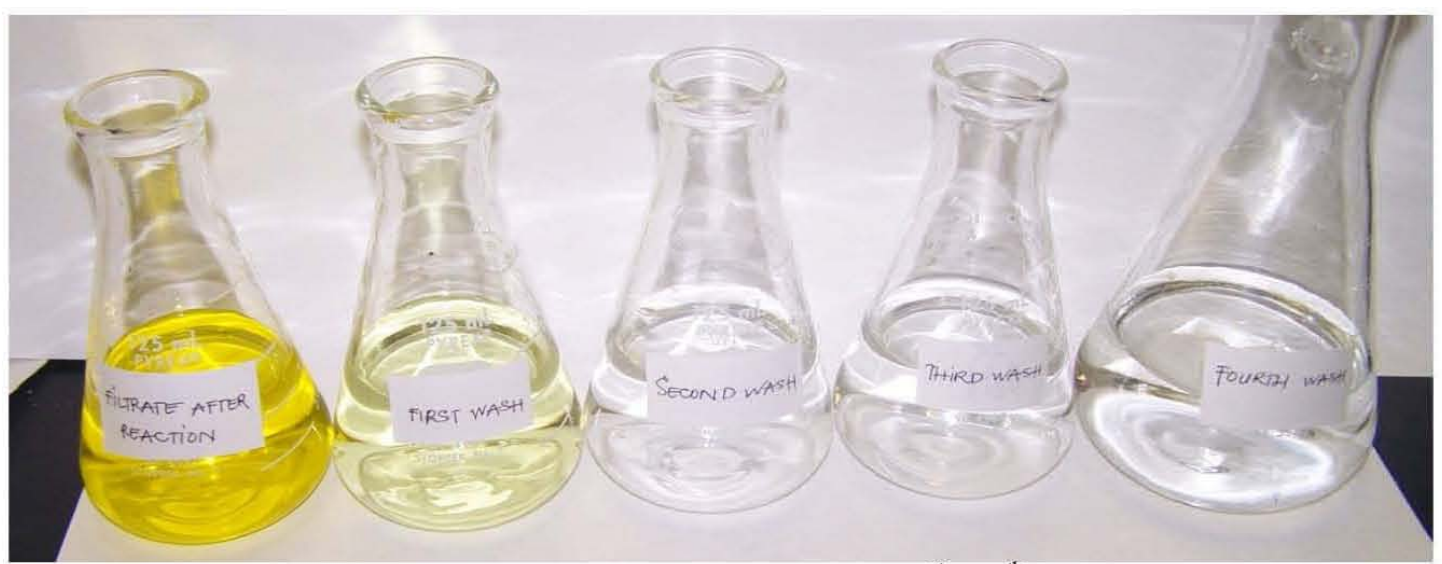

(left to right: filtrate after 4 hours reaction time, $1^{\text {st }}$ to $4^{\text {th }}$ water wash)

The white crystallites of the filter cake were analyzed with SEM (Figure 16), XRD and PLM to identify the phases involved. The filter cake showed 1-2 $\mu \mathrm{m}$-sized crystals, round- to hexagonshaped, with no visible large agglomerates. The crystals had a mixed composition of a P-rich phase and some Na-Al-silicate. However, no sign of hydrotalcite could be observed, i.e., an aluminum-rich phase.

Figure 16. 222-S Laboratory Scoping Tests - Back Scattered Electron Image and Energy Dispersive Spectrometry Spectrum of the Single-Shell Tank Simulant Filter Cake.
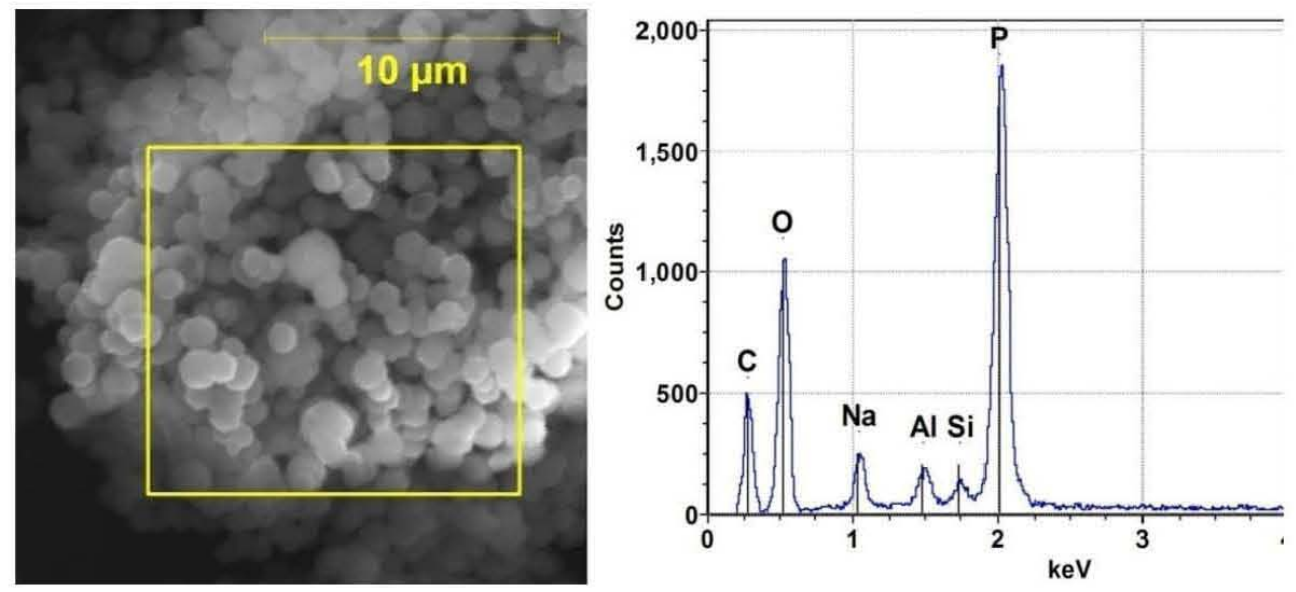

\subsubsection{Second SST Run}

Due to the unexpected results of the initial SST test, the decision was made to run an additional test with the SST simulant. The SST retest was designed to address the Lithium demand for producing Li-hydrotalcite. The test matrix for the retests was set for adding the equivalents of $0.2 \mathrm{M}, 0.3 \mathrm{M}$, and $0.4 \mathrm{M} \mathrm{Li}$ to $330 \mathrm{~mL}$ aliquots; which corresponds to a $\mathrm{Li}: \mathrm{Al}$ ratio of 1:2, 3:4, and 1:1 respectively. The three solutions will henceforth be referred to as $0.2-\mathrm{M} \mathrm{Li}, 0.3-\mathrm{M} \mathrm{Li}$, and $0.4-\mathrm{M} \mathrm{Li}$. 
Addition of the different amounts of Li showed slight visual differences in reaction kinetics. The 0.2-M Li-containing beaker immediately formed white crystallites as in the previous SST run. However, the reaction in the other two beakers was delayed by about 15 to 20 seconds. After 4 hours of crystal ripening, the three beakers had the same appearance (see Figure 17).

Figure 17. 222-S Laboratory Scoping Tests - Single-Shell Tank Simulant Retest Product after Four Hours of Ripening

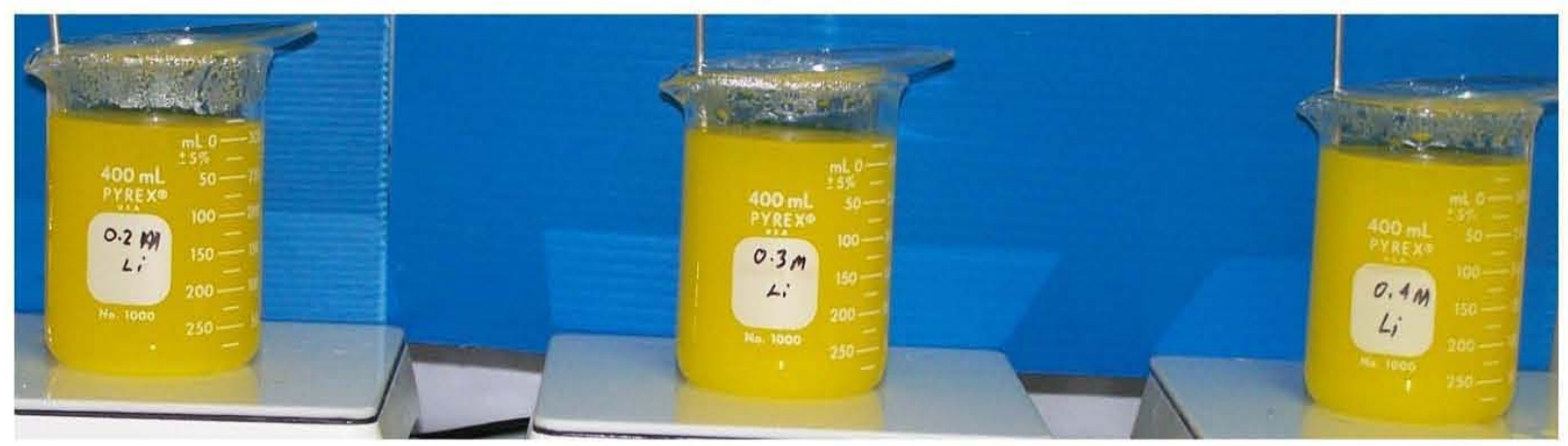

The three different products behaved differently during filtration but filtered rapidly. They produced significantly different amounts of filter cakes, the excess $\mathrm{Li}$ reaction $(0.4 \mathrm{M} \mathrm{Li})$ produced the largest amount of filter cake $(3.47 \mathrm{~g})$ and the clearest filtrate, and the $0.2-\mathrm{M} \mathrm{Li}$ filter cake had the lowest mass $(0.24 \mathrm{~g})$, even lower than the SST original experiment.

SEM, EDS, and XRD analysis did not show any substantial differences between the products in composition, particle shape, and spectrum compared to the first SST run. Even though Lithium Phosphate was shown as the major component, traces of LiHT could be identified on the 0.4-M $\mathrm{Li}$, suggesting there could be a threshold effect on the Li concentration to start the LiHT precipitation. 
Figure 18. Back Scattered Electron Images and Energy Dispersive Spectrometry Spectra of Single-Shell Tank Simulant Retest Filter Cake after Four Hours.
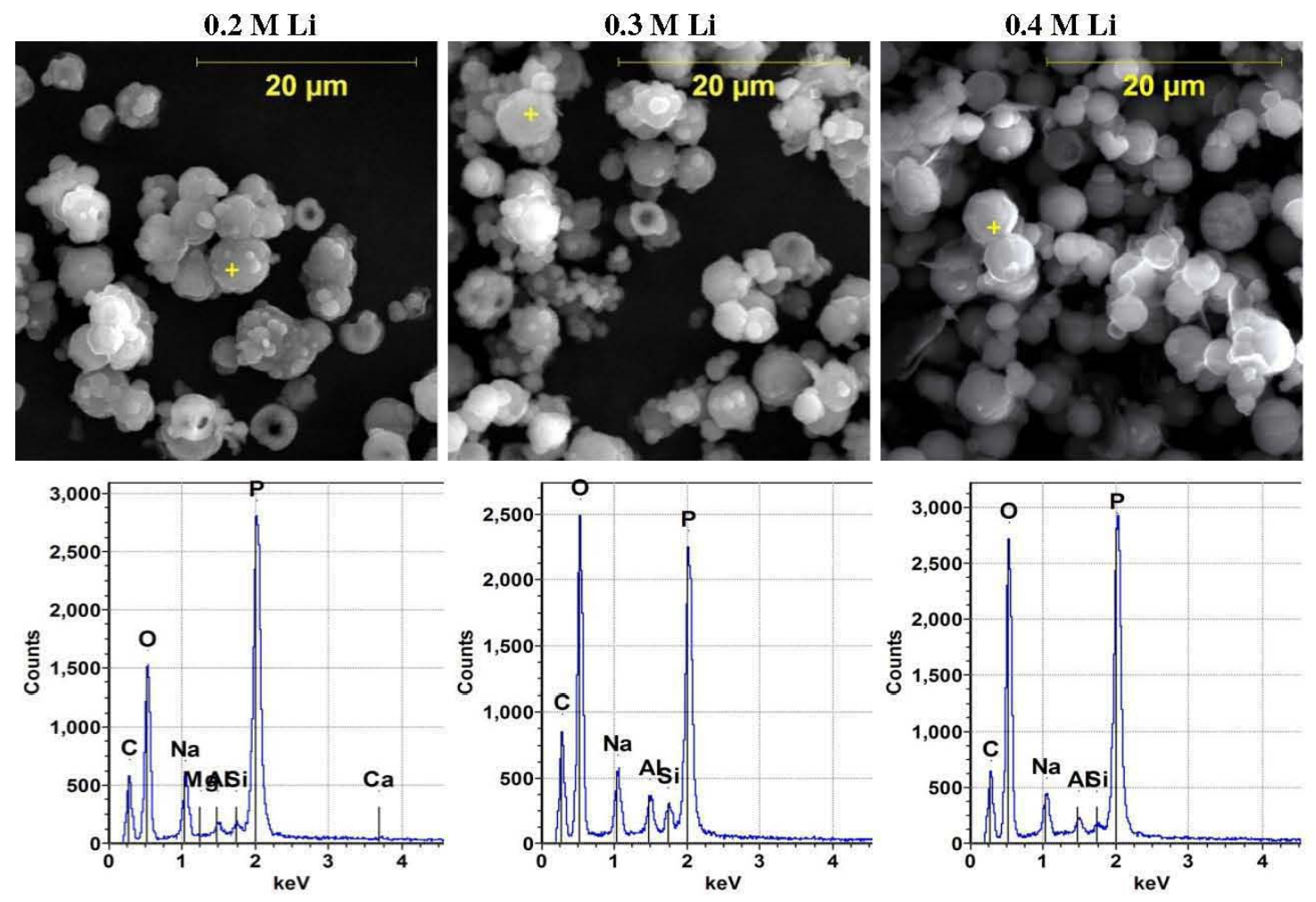

\subsubsection{Conclusions}

For the DST simulant, the amount of aluminum and lithium retained in the filter cake is in the $90+$ mol\% range. This product is composed primarily of lithium-aluminum-carbonate-hydroxide hydrate (i.e., Li-hydrotalcite). The Li-hydrotalcite that formed contains primarily carbonate (TIC) as the intercalated anion. It is unlikely that the nitrate and nitrite retained in the filter cake could be intercalated; however, the XRD results indicated sodium nitrate, $\mathrm{NaNO}_{3}$, as the minor phase.

In the case of the SST simulant, very little aluminum is retained $(\sim 8 \mathrm{~mol} \%)$, but $\sim 75 \mathrm{~mol} \%$ of the lithium and phosphorus precipitated as lithium phosphate. The reason why $25 \mathrm{~mol} \%$ of the lithium did not precipitate could not be identified. The aluminum in the SST supernate generally did not react at all. Some formed cancrinite (NaAl-silicate) with silicon leached from the glass beaker. The SST retest with variable amounts of lithium ( $\mathrm{Li}: \mathrm{Al}=0.5-1$ ) showed that a certain lithium concentration does produce Li-hydrotalcite beside the preferentially formed Liphosphate. However, even in the case of $\mathrm{Li}: \mathrm{Al}=1$, only trace amounts of Li-hydrotalcite were observed. In order to remove the misleading contribution of Si from the glass beakers, the SST test should be rerun using Teflon ${ }^{10}$ reaction vessels and increasing $\mathrm{Li}$ :Al ratios to determine when the maximum production of hydrotalcite occurs.

${ }^{10}$ Teflon is a trademark of the E. I. DuPont De Nemours and Company, Wilmington, Delaware. 
Besides the formation of Li-phosphate, no other competing reactions were evident within this effort. Theoretically, the formation of Li-fluoride and Li-carbonate are potential reactions to interfere with the precipitation of the Li-hydrotalcite. The solubility of the individual lithium salts is highly variable (CRC ${ }^{11}$ Handbook of Chemistry and Physics, 90th Edition), and one of the unknowns to date is the solubility of the LiHT within the conditions of the SST stimulant.

In summary the following recommendations were made:

Optimize reaction and crystal ripening time. Identify the particle-size phases.

- Optimize the heating and cooling cycles of the filtrate.

- Monitor anions to identify the limiting factors for precipitation. Determine whether or not an increase in release of certain anions and cations during the later stages of washes are real or an analytical artifact.

- Investigate the effect of filter cake washes (chemistries, $\mathrm{pH}$, types, and number) on the product. Place special focus on up-flow bed expansion versus down-flow.

- Select reactors with appropriate materials of construction (Teflon, stainless steel) for the SST tests.

- Determine the threshold lithium concentrations for various waste types based upon the lithium demand in the waste. Identify the boundaries of the effects of different ionic strength solutions.

- Obtain XRD and Raman spectra of each potential species of LiHT under the WTP conditions with the anions present in most of the tanks at Hanford site.

${ }^{11} \mathrm{CRC}$ is a registered trademark of the CR Press, Inc., Corporation, Boca Raton, Florida 
RPP-48376, Rev. 0

\subsection{GENERAL CONCLUSIONS AND RECOMMENDATIONS FROM THE TWO SCOPING TESTS}

A process for removing aluminum from tank waste simulants by adding lithium and precipitating Li-Al-dihydroxide (Lithiumhydrotalcite, $\left[\mathrm{LiAl}_{2}(\mathrm{OH})_{6}\right]^{+} \mathrm{X}^{-}$) has been verified. The Georgia Tech tests involved a double-shell tank (DST) stimulant. The Hanford 222-S tests involved DST and single-shell tank (SST) simulants.

In the case of the DST simulant, and for both tests, the product was the anticipated Li-hydrotalcite, rapidly precipitated, separated, and decontaminated in high yield. The Li-hydrotalcite from the DST supernate was an easily filterable solid. After four water washes the filter cake was a fluffy white material made of $<100 \mu \mathrm{m}$ particles made of smaller spheres. These spheres are agglomerates of $\sim 5 \mu \mathrm{m}$ diameter platelets with $<1 \mu \mathrm{m}$ thickness. Chemical and mineralogical analyses of the filtrate, filter cake, and wash waters indicate a removal of $90+\mathrm{wt} \%$ of the dissolved $\mathrm{Al}$ from the DST simulant. The dried product may be suitable for Class C disposal or used as a LAW glass former. The hydroxide-rich filtrate may be recycled to leach additional aluminum sludge or fedforward to WTP for final treatment.

For the SST simulant, the product formed was primarily Li-phosphate. However, adding excess $\mathrm{Li}$ to the solution did result in the formation of traces of Li-hydrotalcite. Further parametric tests should be performed to characterize the two competing reactions, and determine the adequate Lithium addition.

In case of the DST simulant, phosphorus co-precipitated with the hydrotalcite. This would imply the added benefit of the removal of phosphorus along with aluminum in the pre-treatment part of the waste treatment and immobilization plant (WTP).

For this endeavor to be successful, a serious effort toward process parameter optimization is necessary. Among the major issues to be addressed are the dependency of the reaction yield on the solution chemistry, as well as residence times, temperatures, and an understanding of particle growth. 


\subsection{REFERENCES}

AREVA, 2008, PCT International Application PCT/US2008/076589.

AREVA, 2010, Aluminum Removal and Sodium Regeneration from Hanford Waste by Lithium Hydrotalcite Precipitation - Laboratory Scale Validation on Waste Simulants - Test Report, RPP-RPT 48380, Rev. 0.

AREVA, 2010, Aluminum Removal and Sodium Regeneration from Hanford Waste by Lithium Hydrotalcite Precipitation - Technology Readiness Evaluation, RPP-48379, Rev. 0.

AREVA, 2010, Technology Maturation Plan for Aluminum Removal and Sodium Regeneration from Hanford Waste by Lithium Hydrotalcite Precipitation, RPP-PLAN-48085, Rev. 0.

AREVA, 2009, Aluminum Removal and Sodium Regeneration from Hanford Waste by Lithium Hydrotalcite Precipitation, RPT-3001622, Rev. 0.

Huber, H.J., J.B. Duncan, and G.A. Cooke, Washington River Protection Solutions, March 2010, Report on Qualitative Validation Experiments Using Lithium-Aluminum Layer DoubleHydroxides for the Reduction of Aluminum from the Waste Treatment Plant Feedstock, LAB-RPT-10-00003, Rev. 0.

AREVA, 2010, Aluminum Removal and Sodium Regeneration from Hanford Waste by Lithium Hydrotalcite Precipitation - Alternative Process Deployment Scenarios, RPP-RPT 48378, Rev. 0.

U. S. Department of Energy, Office of River Protection, Richland, Washington, 2010, River Protection Project System Plan, Rev. 5, ORP-11242. 
6.0

APPENDIX A: GEORGIA TECH LABORATORY EXPERIMENT BLOCK FLOW DIAGRAM

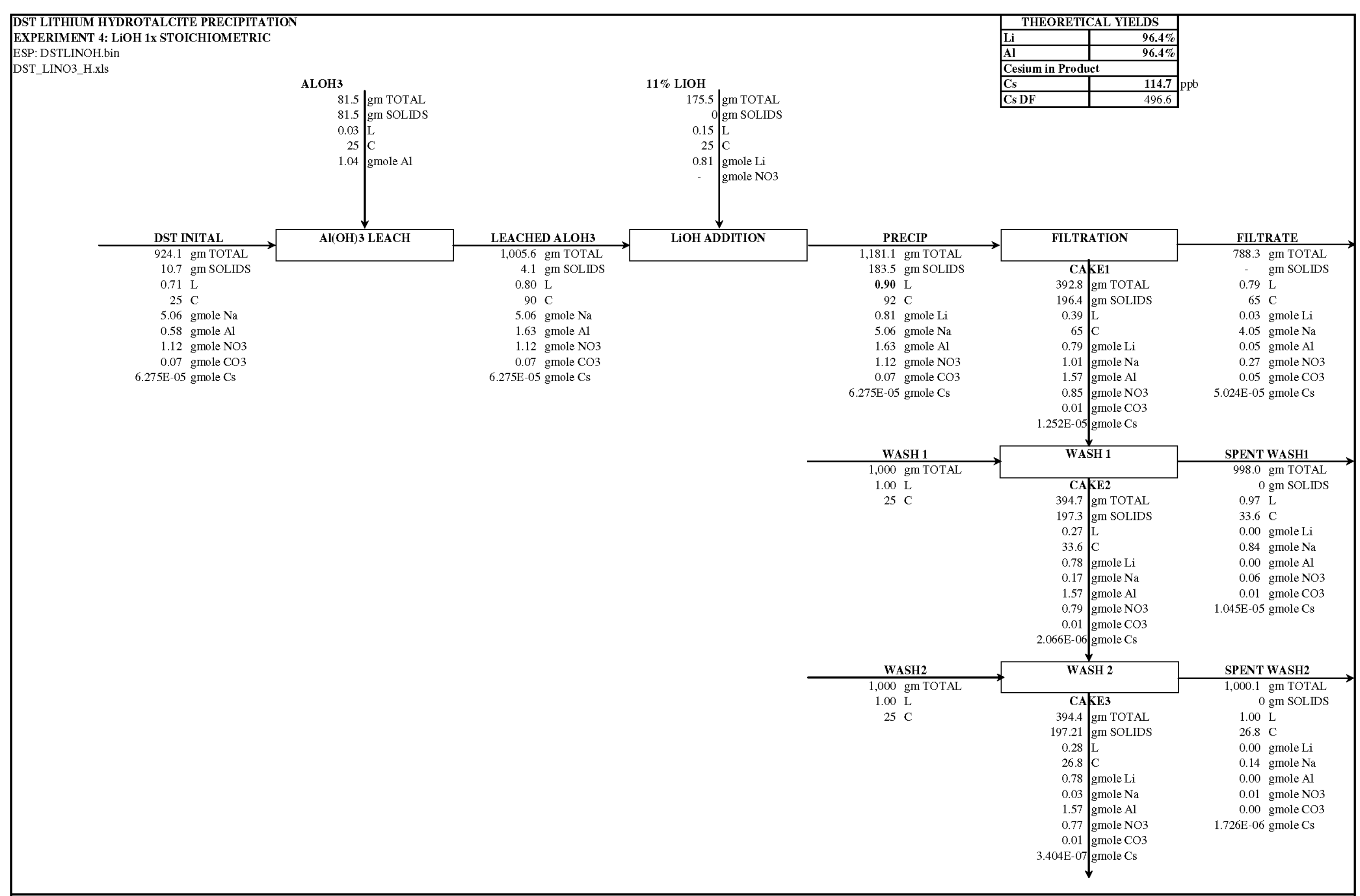


APPENDIX B: GEORGIA TECH LABORATORY EXPERIMENT MASS BALANCE

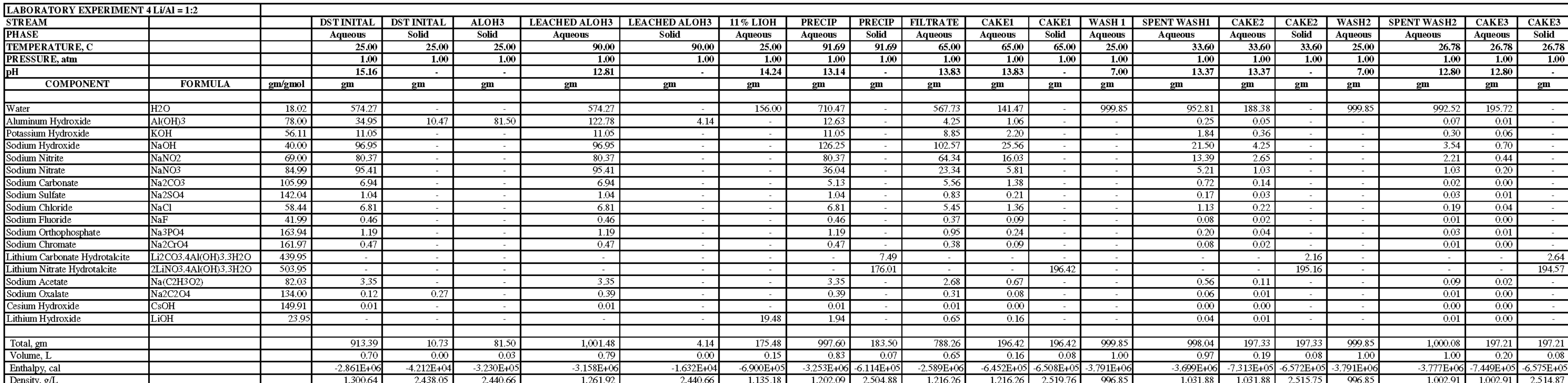

